\title{
PPAR $\gamma$-independent Activity of Thiazolidinediones: A Promising Mechanism of Action for New Anticancer Drugs?
}

\author{
Isabelle Grillier-Vuissoz ${ }^{1}$, Sabine Mazerbourg ${ }^{1}$, Michel Boisbrun ${ }^{2}$, Sandra Kuntz ${ }^{1}$, Yves Chapleur $^{2}$ and Stéphane Flament ${ }^{1 *}$
}

${ }^{1}$ EA 4421 Signalisation, Genomics and Translational Research in Oncology (SIGRETO) Nancy-University, 54506 Vandoeuvre-lès-Nancy, France ${ }^{2}$ Groupe S.U.C.R.E.S, UMR 7565 CNRS, Nancy-Université, 54506 Vandœuvre-lès-Nancy, France

\begin{abstract}
Thiazolidinediones are agonists of the nuclear receptor Peroxisome Proliferator Activated Receptor gamma (PPARY). These synthetic compounds are known for a long time to have anticancer potencies and numerous studies have been performed to understand their mechanism of action. An increasing amount of converging results indicate that most of these mechanisms appear in a PPARy-independent manner. This was suggested by the observation of effects in cell types devoid of PPARY and by the absence of correlation between agonist efficiencies and the intensity of the effects. The PPARy-independence was demonstrated by various experimental approaches using PPARY antagonists, RNA interference targeting PPARY or thiazolidinedione derivatives devoid of PPARY agonist activity. Here, we review the studies that describe PPARy-independent changes including ionic changes (intracellular $\mathrm{pH}$ and $\mathrm{Ca}^{2+}$ ), reactive oxygen species production, Mitogen Activated Protein Kinases activation, endoplasmic reticulum stress and proteasomal degradation of key proteins. The relationships between these events that occur either early or late after thiazolidinedione exposure and their possible involvement in the antineoplastic effect are discussed. We conclude about the possibility to take advantage from these data to develop new thiazolidinedione derivatives usable as anticancer drugs.
\end{abstract}

\section{Introduction}

Thiazolidinediones (TZD) are synthetic compounds characterized by a thiazolidine-2-4-dione ring (Figure 1). They are insulin sensitizers. Looking for efficient hypolipemiants, the Japanese company Takeda identified the first compound of this family: Ciglitazone (CGZ) [1]. Initial studies carried on diabetic-obese rodent showed that CGZ increases insulin sensitivity and reduces plasma triglyceride levels [2]. In 1988, similar effects including lowering plasma glucose, insulin, triglyceride, free fatty acid, lactate, and ketone body levels were obtained with Troglitazone (TGZ) (Sankyo) in insulin-resistant diabetic animal models [3]. The clinical potential of this molecule led to the development of numerous derivatives as Englitazone (Pfizer), Pioglitazone (PGZ) (Takeda Pharmaceuticals) and Rosiglitazone (RGZ) (GlaxoSmithKline). In fine, three of them were used in clinic for the treatment of noninsulin-dependent type 2 diabetes mellitus: TGZ, RGZ and PGZ.

The classic mechanism of action of TZD requires their binding to the Peroxisome Proliferator Activated Receptor gamma (PPAR $\gamma$ ) that is a ligand-activated transcription factor belonging to the steroid hormone receptor superfamily [4-6]. PPAR heterodimerizes with retinoid $X$ receptor (RXR) and binds specific DNA sequences, known as PPAR $\gamma$ response element in the promoter of target genes [7].

Although TZD have revolutionized the treatment of diabetes, mounting evidences on side effects of these drugs led to their progressive withdrawal from the market. The clinical use of TGZ was stopped because of a severe hepatotoxic effect $[8,9]$. The mechanism of TGZ-induced hepatotoxicity is poorly understood and appears to be multifactorial. One of the factors could be the formation of reactive metabolites after enzyme-mediated metabolisation [10,11]. In 2010, RGZ was withdrawn from the European markets in response to increasing concerns about its cardiovascular safety [12]. More recently, PGZ was also withdrawn from the market in France in regards to an increase in bladder cancer rate $[13,14]$.
In addition to their antidiabetic activity, TZD were also shown to inhibit the proliferation and to induce the differentiation of various cancer cells not only in vitro but also in rodent models. Despite these promising preclinical results, clinical trials did not display clear beneficial effects on patients treated for breast cancer, colorectal cancer or liposarcomas [15-17]. However, a survey trial for diabetic patients showed a significant decrease of pancreatic cancer for patients treated with RGZ compared to the control group [18]. Moreover a metaanalysis including about 30000 patients reported an overall lower incidence of cancer in diabetic patients treated with RGZ than in the control group [19]. On advanced prostate cancer, a phase II trial showed that TGZ treatment stabilized the prostate-specific antigen (PSA) level. In addition, one patient had a dramatic decrease in PSA serum concentration to nearly undetectable levels [20]. A modest effect of RGZ has been observed for patients with thyroid cancer [21]. Interestingly, in this study, no relationships were found between the level of PPAR $\gamma$ and the response to RGZ, suggesting a potential PPAR $\gamma$-independent mechanism. This hypothesis is in agreement with the fact that a phase I clinical trial did not show any beneficial effects of an association with the RXR selective compound Bexarotene in patients with refractory cancers [22].

*Corresponding author: Stéphane Flament, EA 4421 Signalisation, Genomics and Translational Research in Oncology (SIGRETO) Nancy-University, Faculty of Science, BP 70239, 54506 Vandoeuvre-lès-Nancy, France, E-mail: stephane.flament@scbiol.uhp-nancy.fr

Received December 01, 2011; Accepted January 19, 2012; Published January 21, 2012

Citation: Grillier-Vuissoz I, Mazerbourg S, Boisbrun M, Kuntz S, Chapleur Y, et al. (2012) PPARy-independent Activity of Thiazolidinediones: A Promising Mechanism of Action for New Anticancer Drugs? J Carcinogene Mutagene S8:002. doi:10.4172/2157-2518.S8-002

Copyright: (C) 2012 Grillier-Vuissoz I, et al. This is an open-access article distributed under the terms of the Creative Commons Attribution License, which permits unrestricted use, distribution, and reproduction in any medium, provided the original author and source are credited. 


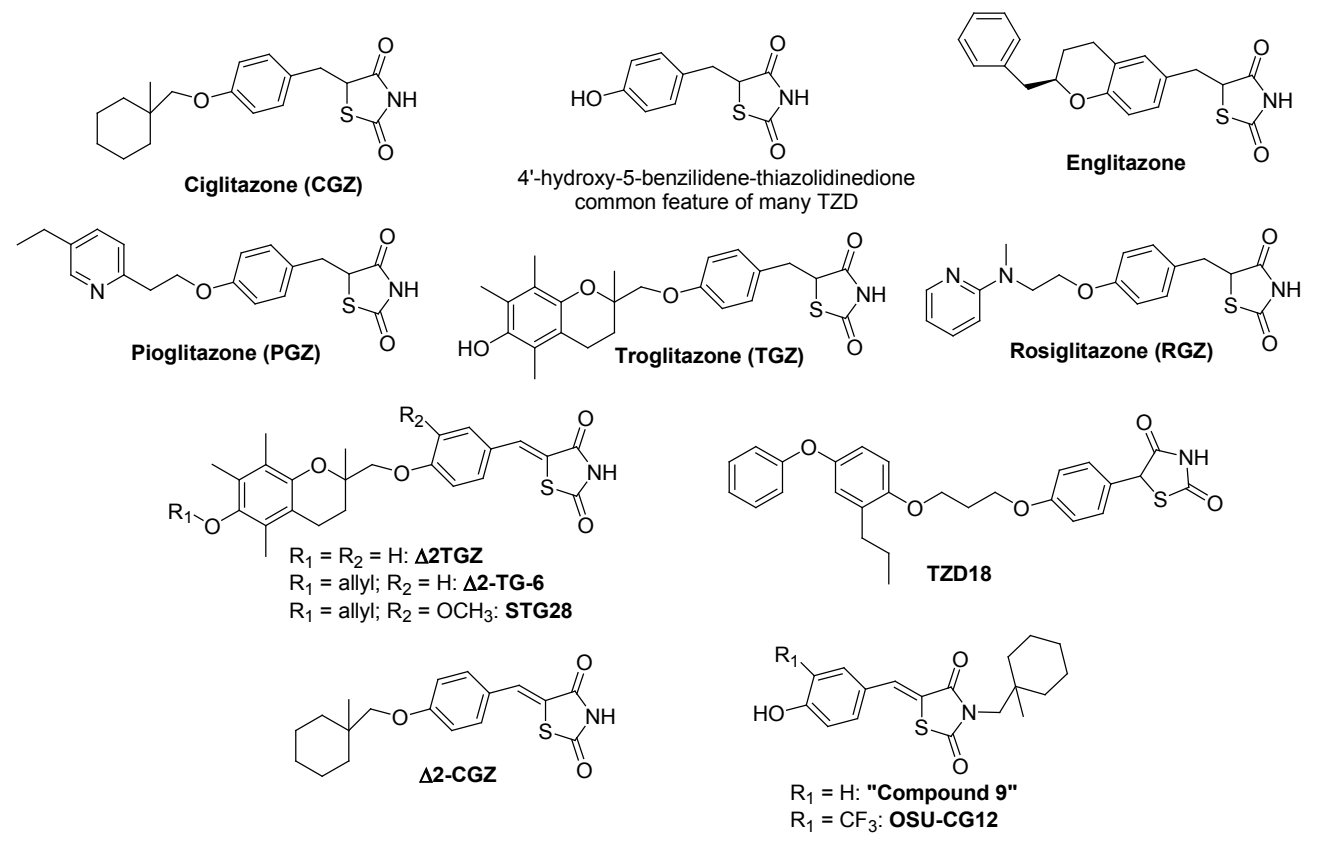

Figure 1: Structures of the main TZD reported in this review.

The anticancer effects of TZD can be associated with several processes including cell differentiation, cell cycle arrest, apoptosis and autophagy. The involvement of PPAR $\gamma$ in these effects of TZD is really unclear since increasing PPAR $\gamma$-independent events have been reported. Intensive researches are now focusing on the underlying molecular mechanisms. Here we review the current knowledge about major PPAR $\gamma$-independent effects of TZD. The role of some of them is still unclear whereas others have been clearly involved in the anticancer action. These data will be essential in order to develop new TZD derivatives devoid of toxicity and more efficient in cancer therapeutics.

\section{Apoptosis}

Many drugs used in anticancer therapies exert their effect by inducing apoptosis. Numerous studies performed in various cell lines have described that the effects of TZD are associated with apoptosis but the mechanisms leading to the cell death have not always been identified. Apoptosis can be induced by two main pathways. First, the intrinsic pathway involves signaling through the mitochondria. Members of the Bcl-2 family induce the release of cytochrome $\mathrm{c}$ from the mitochondrial membrane leading to the activation of caspase 9. Once activated, caspase 9 targets downstream effectors such as caspases 3 and 7. Second, the extrinsic pathway is mediated by death receptors belonging to the tumor necrosis factor receptor (TNFR) superfamily which includes Fas, TNFR1, Death receptor (DR) 3, DR4, DR5 and DR6. Upon ligand binding and trimerisation, the intracellular domain recruits adaptator proteins such as Fas-associated death domain (FADD). In turn, caspases 8 and 10 are activated leading to the activation of the effector caspases 3 and 7. In some cases, caspase 8 can also cleave Bid, leading to Bax activation and the release of cytochrome c. Negative regulators have been identified. Cellular FLICE inhibitory protein (c-FLIP) is an inactive analogue of caspase 8 that inhibits the extrinsic pathway. Inhibitors of apoptosis (IAP) such as survivin mainly suppress the activity of caspases.
In prostate cancer cells, some TZD can induce apoptosis by the intrinsic pathway in a PPAR $\gamma$-independent manner [23]. This was concluded from several observations. First, despite deficiency in PPAR $\gamma$, LNCaP cells exhibit a higher degree of susceptibility to TGZmediated apoptosis compared to the PPAR $\gamma$-rich PC-3 cells. Second, $\triangle 2$-TGZ, although devoid of PPAR $\gamma$ agonist activity is more potent than TGZ in inducing cytochrome $c$ release and DNA fragmentation. Similar results are obtained with CGZ and $\Delta 2$-CGZ. Third, RGZ and PGZ which are more potent PPAR $\gamma$ agonists than CGZ and TGZ, show only marginal effects on apoptotic cell death. TGZ does not cause appreciable changes in the expression level of Bcl-2 family members (Bcl-2, Bcl-xL, Bax, Bak, Bad, Bid). Nevertheless, TGZ, CGZ and their $\Delta 2$ counterparts inhibit the antiapoptotic functions of $\mathrm{Bcl}-\mathrm{xL}$ and $\mathrm{Bcl}-2$ by disrupting the $\mathrm{BH} 3$ domain-mediated interactions with the proapoptotic members of Bcl-2 family [23-25]. The treatment of PC-3 cells with TGZ and $\Delta 2$-TGZ is also associated with caspase 9 activation and a pretreatment with the pan-caspase inhibitor Z-VAD-FMK protects these cells from apoptosis [23]. Finally, in the PPAR $\gamma$-deficient cell line $\mathrm{LNCaP}, \mathrm{Bcl}-\mathrm{xL}$ overexpression protects the cells from TGZand $\Delta 2$-TGZ-induced apoptosis [23].

TZD-induced apoptosis can also be associated with the extrinsic pathway. Indeed, an increase in DR5 expression has been reported in breast cancer cells MCF-7 and MDA-MB-231 exposed to TZD18, a dual PPAR $\alpha / \gamma$ agonist that inhibits cell proliferation in a PPAR-independent manner [26]. However, in both cell lines, exposure to TZD18 leads to the activation of caspases 8 and 9 indicating also the activation of the intrinsic pathway. The inhibition of caspases by the pan-caspase inhibitor Z-VAD-FMK completely inhibits TZD18-induced apoptosis. In bladder cancer cells (RT4, T24), TGZ also induces apoptosis via intrinsic and extrinsic pathways, independently of PPAR $\gamma$ [27]. The underlying mechanisms involve the up-regulation of tumor necrosis factor-related apoptosis-inducing ligand (TRAIL), the increased cell surface expression of DR5 and the proteasomal degradation of c-FLIP and survivin. Caspases 8 and 9 are also activated. 
Citation: Grillier-Vuissoz I, Mazerbourg S, Boisbrun M, Kuntz S, Chapleur Y, et al. (2012) PPARy-independent Activity of Thiazolidinediones: A Promising Mechanism of Action for New Anticancer Drugs? J Carcinogene Mutagene S8:002. doi:10.4172/2157-2518.S8-002

\section{Autophagy}

Autophagy is a major catabolic pathway by which eukaryotic cells degrade and recycle macromolecules and organelles. This pathway is activated under environmental stress conditions, during development and in several pathological situations. During the autophagic process, portions of the cytoplasm are surrounded by the isolation membrane to form autophagosomes, which then fuse with lysosomes. Elongation of the autophagosome membrane is mediated by two conjugation pathways activated by Atg7 (Autophagy-related gene 7): Atg12 conjugated to Atg5 and Atg8/LC3 conjugated to phosphatidylethanolamine (PE). The Atg12-Atg5 dimer binds to Atg16L which anchors the protein complex and targets Atg8/LC3-PE on the forming isolation membrane. Atg8/LC3 is a soluble form of microtubule-associated protein 1 light chain 3 (LC3-I) converted to a cleaved phosphatidylethanolamineconjugated membrane-bound form (LC3-II). The shorter LC3-II form is associated with the presence of autophagosomes and is used as a marker of autophagy. Another marker is the expression level of beclin1, involved in the activation of the class III PI3K necessary to recruit the components of the two conjugation cascades. As molecular sensor of cellular energy, mammalian homologue of target of rapamycin (mTOR) plays an essential role in the control of autophagy. The mTOR pathway is activated by growth factors (via PI3K/AKT and ERK1/2 pathways) leading to mTOR phosphorylation and inhibition of autophagy. Elevated AMP/ATP ratio activates AMP-activated kinase a (AMPKa) and the $\mathrm{mTOR}$ negative regulator, tuberous sclerosis complex $1 / 2$ (TSC1/TSC2) $[28,29]$. The role of PPAR $\gamma$ in TZD-induced autophagy is conflicting and is likely to depend on the cellular context. In porcine aorta endothelial (PAE) cells, TGZ promotes autophagosome formation and accumulation of the autophagy marker, LC3-II, after 4 hours of treatment [30]. Autophagy still occurs in the presence of the irreversible antagonist of PPARy GW9662. TGZ-induced autophagy is accompanied by an increase of AMPKa phosphorylation and by a decrease in the phosphorylation of mTOR and its target, the ribosomal protein S6 kinase (p70S6K). Accumulation of LC3-II is suppressed by the use of the specific AMPKa inhibitor, compound C, and by AMPKa RNA interference. Atg5 participates in LC3-II accumulation observed after TGZ treatment but beclin 1 expression is not modified. Overall, these data demonstrate that TGZ-induced autophagy is correlated with AMPKa activation and is independent of PPAR $\gamma$ [30]. In prostate cancer cells LNCaP, the PPAR $\gamma$-inactive CGZ derivative OSU-CG12 also induces LC3-II accumulation, which can be blocked by the autophagy inhibitor, 3-methyladenine [31]. Exposure of LNCaP cells to $10 \mu \mathrm{M}$ OSU-CG12 leads to the phosphorylation of AMPKa on Thr172 following 10-20 minutes. The activation of AMPK is corroborated by the concomitant dephosphorylation of mTOR and p70S6K. Dominantnegative and pharmacological inhibition of AMPKa activation prevent the conversion of LC3-I to LC3-II. Furthermore, the knockdown of a target of AMPKa, TSC2, blocks the accumulation of LC3-II. Then, AMPKa and TSC2 are presented as major regulators of OSU-CG12induced autophagy. Moreover, ectopic expression of a dominantnegative AMPKa reduces the inhibitory action of OSU-CG12 on LNCaP cell viability whereas it does not affect PARP cleavage [31]. In contrast to the previous data, autophagy is mediated by PPAR $\gamma$ activation in the breast cancer cells MDA-MB-231 [32]. A treatment with TGZ or RGZ leads to the formation of autophagosomes observed by acridine orange staining, electron microscopy and LC3 localisation [32]. A similar result is obtained after overexpression of a constitutive
$\operatorname{PPAR} \gamma$ receptor $(\mathrm{P} \gamma \mathrm{CA})$ in the non-tumorigenic epithelial cell line MCF-10A suggesting that PPAR $\gamma$ is required and sufficient to induce autophagy. The author's further show by RNA interference that the Hypoxia-inducible factor-1 (HIF1 $\alpha$ ) is the target of PPAR $\gamma$ necessary for autophagosome formation after RGZ exposure in MDA-MB-231 cells [32]. In other cellular models, the PPAR $\gamma$-dependence of TZDinduced autophagy is uncertain: in pancreatic cancer cells BxPC-3 exposed to TGZ and in adrenocortical cancer cells exposed to RGZ $[33,34]$.

Thus, autophagy and apoptosis appear as two complementary processes involved in the activity of TZD. Hereafter we will focus on earlier events that are triggered by TZD in a PPAR $\gamma$-independent way and we will determine their respective importance in the anticancer effect as well as their eventual interconnections.

\section{Ionic Changes}

It is well known that elevated intracellular $\mathrm{pH}(\mathrm{pHi})$ favors DNA synthesis and promotes tumor growth [35]. In bovine aortic endothelial (BAE) cells, the effect of TGZ and $\mathrm{RGZ}$ on the $\mathrm{Na}^{+} / \mathrm{H}^{+}$exchanger (NHE) have been studied [36]. For this purpose, BAE cells were incubated in $\mathrm{Na}^{+}$-free medium which induces acidosis and then $\mathrm{Na}^{+}$was added to activate the NHE. TZD were added simultaneously to test their effect on the activity of the NHE. TGZ $(10 \mu \mathrm{M})$ has a small but significant inhibitory effect whereas RGZ at a three-fold higher concentration has no significant effect. Since RGZ is a more potent PPAR $\gamma$ agonist, this suggests a PPAR $\gamma$-independent mechanism. Interestingly, TGZ induces a decrease in the proliferation of BAE cells with $50 \%$ of inhibition after a 48 hours exposure to $10 \mu \mathrm{M}$, whereas RGZ is inefficient. In the breast cancer cell lines MCF-7 and MDA-MB-231, TGZ also induces acidosis [37]. The use of the fluorescent probe BCECF indicates that pHi decreases promptly after $25 \mu \mathrm{M}$ TGZ exposure, falling after 12 minutes from $7.49 \pm 0.1$ to $6.77 \pm 0.03$ for MCF-7 cells and from 7.38 \pm 0.07 to $6.89 \pm 0.09$ for MDA-MB-231 cells. These $\mathrm{pH}$ changes are not the result from lactate production but from a decreased $\mathrm{H}^{+}$extrusion due to NHE inhibition. This effect is still observed in the presence of the PPAR $\gamma$ antagonist GW9662. In MCF-7 cells, TGZ-induced acidosis still occurs in the presence of either the EGFR antagonist AG1478 or the MAPK inhibitors PD98059 and U0126 [38]. Although some TZD have been shown to induce a decrease in $\mathrm{pH}$ in several cell types and to inhibit cell proliferation, the link between TZD-triggered acidosis and the antiproliferative activity has not been established.

$\mathrm{Ca}^{2+}$ is a highly versatile signaling molecule controlling numerous functions during life and death of cells. Increases of cytosolic $\mathrm{Ca}^{2+}$ during cell death can arise from several sources, including damage of external membranes, activation of cation channels, or release from intracellular stores, especially the endoplasmic reticulum (ER). Accumulating evidences indicate a highly coordinated communication between ER and mitochondria [39]. The release of $\mathrm{Ca}^{2+}$ from ER has been shown to be directly responsible for mitochondrial $\mathrm{Ca}^{2+}$ overload which leads to the opening of the permeability transition pore and releasing cytochrome c. Several studies have contributed to demonstrate that TZD induce an increase in intracellular $\mathrm{Ca}^{2+}$ (Table 1). Using the fluorescent probe Fura2, the authors show that TGZ and CGZ very rapidly deplete intracellular $\mathrm{Ca}^{2+}$ stores in both PPAR $\gamma^{+/+}$ and PPAR $\gamma^{-1-}$ mouse embryonic stem (ES) cells, suggesting a PPAR $\gamma$ independent effect [40]. Since both TGZ and CGZ inhibit cell growth and block cell cycle in the G1 phase in both PPAR $\gamma^{+/+}$and PPAR $\gamma^{-1}$ 
Citation: Grillier-Vuissoz I, Mazerbourg S, Boisbrun M, Kuntz S, Chapleur Y, et al. (2012) PPARy-independent Activity of Thiazolidinediones: A Promising Mechanism of Action for New Anticancer Drugs? J Carcinogene Mutagene S8:002. doi:10.4172/2157-2518.S8-002

Page 4 of 15

\begin{tabular}{|c|c|c|c|c|c|c|c|c|}
\hline Compound & Cell type & ERK1/2 & p38 & JNK & EGFR & $\mathrm{Ca}^{2+}$ & ROS & Reference \\
\hline \multirow{12}{*}{ TGZ } & Rat liver epithelial cells GN4 & 0 & + & & 0 & + & & {$[43,45]$} \\
\hline & Hepatic cells HepG2 & 0 & + & + & & & & [66] \\
\hline & Porcine aorta endothelial stable cell lines expressing EGFR (PAE-EGFR) & + & & & + & & & [65] \\
\hline & Colorectal cancer cells HCT15 and HT29 & + & & & & & & [58] \\
\hline & Colorectal cancer cells HCT-116 & + & & & & & & [59] \\
\hline & Breast cancer cells MCF-7 & + & + & + & & & & [61] \\
\hline & Breast cancer cells MCF-7 & + & & & + & & & [38] \\
\hline & Breast cancer cells MCF-7 & + & & & & + & & $[47)]$ \\
\hline & Prostate cancer cells LNCaP & + & + & & & & & [31] \\
\hline & Normal human urothelial cells (NHU) & + & + & & & + & & {$[46]$} \\
\hline & Lung cancer A549 and 3 T3 cells & & & & & + & & {$[41,42]$} \\
\hline & Mouse embryonic stem cells & & & & & + & & {$[40]$} \\
\hline \multirow{3}{*}{$\Delta 2-T G Z$} & Lung cancer A549 and 3 T3 cells & & & & & + & & {$[41,42]$} \\
\hline & Rat liver epithelial cells GN4 & 0 & + & & 0 & & & {$[43,45]$} \\
\hline & Breast cancer cells MCF-7 & + & & & 0 & + & & {$[47]$} \\
\hline \multirow{11}{*}{ CGZ } & Mouse preadipocyte cell line 1B8 Cultured primary astrocytes & + & + & + & & & + & {$[60]$} \\
\hline & Myoblast C2C12 & + & & & & & + & {$[52]$} \\
\hline & Rat liver epithelial cells GN4 & + & + & & + & + & + & {$[43,45,64]$} \\
\hline & PAE-EGFR cells & + & & & & & & {$[65]$} \\
\hline & Breast cancer cells MCF-7 & + & & & & & & {$[47]$} \\
\hline & Fibrosarcoma cells HT1080 & + & & & & & + & {$[51]$} \\
\hline & Astroglioma cells C6 & & & & & & + & {$[53,54]$} \\
\hline & Glioma cells A172 & + & + & & & & & {$[56]$} \\
\hline & Prostate cancer cells LNCaP & + & + & & & & & {$[31]$} \\
\hline & Normal human urothelial cells (NHU) & + & + & & & + & & {$[46]$} \\
\hline & Lung cancer cells A549 and 3 T3 cells & & & & & + & & {$[42]$} \\
\hline$\triangle 2-C G Z$ & Rat liver epithelial cells GN4 & + & + & & + & & & {$[43,45]$} \\
\hline \multirow{11}{*}{ RGZ } & Renal cancer cells (CaKi cells) & & & & & & + & {$[50]$} \\
\hline & Astroglioma cells C6 & & & & & & + & {$[53,54]$} \\
\hline & Rat liver epithelial cells GN4 & & 0 & & + & & & {$[45]$} \\
\hline & Lung cancer cells A549 & & & & & 0 & & {$[42]$} \\
\hline & Lung cancer cells H1838 (NSCLC) & + & + & & & & & {$[63]$} \\
\hline & Cultured primary astrocytes & 0 & 0 & & & & & {$[60]$} \\
\hline & Hepatic cells HepG2 & & 0 & 0 & & & & {$[66]$} \\
\hline & PAE-EGFR cells & 0 & & & & & & {$[65]$} \\
\hline & Colorectal cancer cells HT-29 & + & + & & & & + & {$[49]$} \\
\hline & Breast cancer cells MCF-7 & 0 & & & & & & {$[47]$} \\
\hline & Normal human urothelial cells (NHU) & + & + & & & + & & {$[46]$} \\
\hline \multirow{3}{*}{ PGZ } & Astroglioma cells $\mathrm{C} 6$ & & & & & & + & {$[54]$} \\
\hline & Rat liver epithelial cells GN4 & & 0 & & & & & {$[45]$} \\
\hline & PAE-EGFR cells & 0 & & & & & & {$[65]$} \\
\hline TZD18 & Breast cancer cells (MDA-MB231, MCF-7) & + & + & + & & & & {$[26]$} \\
\hline STG28 & Prostate cancer cells LNCaP & + & + & & & & & {$[31,62]$} \\
\hline \multirow{2}{*}{ OSU-CG12 } & Prostate cancer cells LNCaP & + & + & & & & & {$[31]$} \\
\hline & Breast cancer cells MCF-7 & + & + & & & & & {$[31]$} \\
\hline
\end{tabular}

Table 1: Early PPARy-independent effects of various TZD. In the different cell lines, + indicates either that MAPK activation, EGFR activation, Ca ${ }^{2+}$ increase or ROS production have been demonstrated whereas 0 indicates that the event does not occur. Absence of symbol indicates that there is no data. 
Citation: Grillier-Vuissoz I, Mazerbourg S, Boisbrun M, Kuntz S, Chapleur Y, et al. (2012) PPARy-independent Activity of Thiazolidinediones: A Promising Mechanism of Action for New Anticancer Drugs? J Carcinogene Mutagene S8:002. doi:10.4172/2157-2518.S8-002

mouse ES cells, the authors concluded that this PPAR $\gamma$ - independent $\mathrm{Ca}^{2+}$ store-depleting effect could account for the antiproliferative action of these TZD. These observations led to the synthesis of TZD derivatives whose biological activities were evaluated for intracellular $\mathrm{Ca}^{2+}$ store depletion [41]. In this study, the $\mathrm{Ca}^{2+}$ assay was performed in $3 \mathrm{~T} 3$ cells, in $\mathrm{Ca}^{2+}$-free medium and in the presence of EGTA that sequesters extracellular $\mathrm{Ca}^{2+}$. In these conditions, TGZ still induces a rapid increase in intracellular $\mathrm{Ca}^{2+}$, further demonstrating that $\mathrm{Ca}^{2+}$ is released from intracellular stores [41]. In another study from the same team, it is reported that RGZ, a more potent PPAR $\gamma$ agonist, does not induce $\mathrm{Ca}^{2+}$ release [42]. Interestingly, unsaturated TZD derivatives $(\triangle 2$-TZD) (that are now known to be PPAR $\gamma$-inactive compounds) are also potent inducers of $\mathrm{Ca}^{2+}$ release $[41,42]$.

In rat liver epithelial cells GN4, CGZ and TGZ also induce a rapid increase in intracellular $\mathrm{Ca}^{2+}$ concentration by depletion of intracellular stores ( 2 minutes after addition of $50 \mu \mathrm{M}$ of either compound, $\mathrm{Ca}^{2+}$ peaks at $150 \mathrm{nM}$ in absence of external $\mathrm{Ca}^{2+}$ ) [43]. However, in the presence of external $\mathrm{Ca}^{2+}$, only CGZ is able to trigger a second increase in intracellular $\mathrm{Ca}^{2+}$ that peaks at $700 \mathrm{nM}$. This suggests that in contrast to CGZ, TGZ blocks store operated channels (SOC) as described in aortic endothelial cells and in mouse ES cells $[40,44]$. Moreover, CGZ and TGZ $(50 \mu \mathrm{M})$ significantly increase CAMKII activity in these cells, 2-fold over vehicle-treated cells, within 10 minutes [45]. The PPAR $\gamma$-inactive derivatives $\triangle 2$-CGZ and $\Delta 2$-TGZ also increase $\mathrm{Ca}^{2+}$ Calmodulin Kinase II (CAMKII) activity but they were less effective than their parent compounds.

Several TZD have also been studied for their effect on intracellular $\mathrm{Ca}^{2+}$ in Normal Human Urothelial (NHU) cells [46]. CGZ and TGZ trigger a rapid increase in intracellular $\mathrm{Ca}^{2+}$ in these cells: it is observed in 1 minute and it is sustained. However, CGZ is a more potent inducer of $\mathrm{Ca}^{2+}$ release than TGZ $(30 \mu \mathrm{M}$ and $100 \mu \mathrm{M}$ are required respectively to trigger responses of similar intensity). In the absence of $\mathrm{Ca}^{2+}$ in the extracellular medium, the $\mathrm{Ca}^{2+}$ increase triggered by CGZ becomes transient instead of sustained. In contrast, RGZ (up to $100 \mu \mathrm{M}$ ) does not induce any increase in intracellular $\mathrm{Ca}^{2+}$. Although the authors demonstrate that the induction by CGZ of NHU cell apoptosis is still observed in the presence of the PPAR $\gamma$ antagonist T0070907, they do not show that the $\mathrm{Ca}^{2+}$ increase also occurs in a PPAR $\gamma$-independent manner.

In the breast cancer cell line MCF-7, using the fluorescent probe Fura2, we have also recently shown that TGZ and its PPAR $\gamma$ inactive derivative $\Delta 2$-TGZ (both used at $25 \mu \mathrm{M}$ ) induce a rapid elevation of cytosolic $\mathrm{Ca}^{2+}$ [47]. This is observed even in the absence of external $\mathrm{Ca}^{2+}$, showing that $\mathrm{Ca}^{2+}$ is also released from intracellular stores in this model. However, the kinetics of recovery after TZD elimination are different with a slower recovery rate in cells exposed to $\Delta 2$-TGZ than in those exposed to TGZ.

What is the importance of the $\mathrm{Ca}^{2+}$ increase in the anticancer effect of TZD? Very few studies have addressed this question. In a structure/ activity relationships study, the capacity to induce $\mathrm{Ca}^{2+}$ release was evaluated together with the growth inhibition (GI) activity [42]. In comparison to TGZ and CGZ that display $\mathrm{GI}_{50}$ of 15 and $20 \mu \mathrm{M}$ respectively, 8 derivatives that do not induce $\mathrm{Ca}^{2+}$ release also do not affect cell proliferation $\left(\mathrm{GI}_{50}>100 \mu \mathrm{M}\right)$. This relation is less clear in another study in which two compounds having lower $\mathrm{GI}_{50}$ compared to TGZ do not induce $\mathrm{Ca}^{2+}$ release [41]. Interestingly, in NHU cells, both CGZ and TGZ induce $\mathrm{Ca}^{2+}$ release and are more potent apoptosis inducers than RGZ that does not affect $\mathrm{Ca}^{2+}$ levels [46]. Besides, the SOC inhibitor 2-APB reduces the CGZ-induced apoptosis of NHU cells [46]. Finally, CGZ has been described to inhibit leiomyoma cell proliferation by a mechanism involving capacitive $\mathrm{Ca}^{2+}$ entry [48].

\section{ROS Production}

Accumulating evidences have shown that TZD can increase the production of intracellular oxygen radicals by cancerous and normal cells. In colon HT-29 cells, the production of reactive oxygen species (ROS) after RGZ exposure has been monitored by flow cytometry using the fluorescent dyes 2',7'-dichlorofluorescein diacetate (DCFH) (hydrogen peroxide and hydroxyl radicals detection) and dihydroethidium (DHE) (superoxyde anion O2 detection). A 1 hour treatment with RGZ (10 or $50 \mu \mathrm{M})$ selectively increases intracellular superoxyde levels, maintained even after $12 \mathrm{~h}$, but it does not affect hydrogen peroxide and hydroxyl radicals [49]. This ROS formation is associated with mitochondrial hyperpolarization detectable using the probe 3,3'-dihexyloxacarbocyanine iodide $\left(\right.$ DIOC $\left._{6}\right)$ : it is observed after 4 hours and is more pronounced after 12 hours of treatment. In human renal cancer cells (CaKi cells), ROS production is also enhanced after 24 hours of exposure to RGZ $(100-300 \mu \mathrm{M})$. No data on earlier points are available [50].

CGZ is also a potent inducer of ROS production in several cell lines. In the HT1080 fibrosarcoma cells, the DCFH probe shows the production of ROS after 24 and 48 hours of CGZ treatment ( $4 \mu \mathrm{M})$ [51]. In comparison, very small amount of ROS are produced in response to RGZ and TGZ whereas PGZ does not induce ROS production. In the myoblast cell line C2C12, CGZ $(10 \mu \mathrm{M})$ induces superoxyde anion but not hydrogen peroxide in less than 30 minutes, as observed by chemiluminescence [52].

A more complete study of ROS generation has been performed in primary astrocytes and C6 glioma cells [53,54]. In both cell types, flow cytometry analysis of DCFH-loaded cells reveals the production of a higher level of ROS after 1 hour of incubation with $20 \mu \mathrm{M}$ CGZ compared to $20 \mu \mathrm{M}$ RGZ [53]. A similar effect is observed in C6 glioma cells after a 15 minutes treatment with CGZ, RGZ, or PGZ at $20 \mu \mathrm{M}$ [54]. At a lower dose $(10 \mu \mathrm{M}), \mathrm{CGZ}$ is still highly efficient, PGZ has a moderate effect and RGZ is ineffective. This analysis is completed with the detection of the $\mathrm{O}_{2}^{-}$through DHE fluorescence. CGZ is the only compound tested generating the superoxyde anion which, at least in part, combines with NO to form peroxynitrite (ONOO-). The CGZinduced ROS increase is prevented by the mitochondrial uncoupling agent FCCP and by the non-metabolizable 2-deoxy-glucose (energy restriction), suggesting that it is dependent on mitochondrial electron transport. The target of CGZ in the mitochondrial respiratory complex is unknown. Interestingly, a TZD binding site, named mitoNEET, has been identified in mitochondria and could be a candidate [55]. Within minutes, tested compounds also provoke mitochondrial depolarization and lower mitochondrial $\mathrm{pH}$ in $\mathrm{C} 6$ glioma cells. The authors suggest that the inhibition of the respiratory chain by CGZ (more efficient), RGZ and PGZ produces ROS, depolarization, and decreases mitochondrial $\mathrm{pH}$ at the same time [54].

What is the importance of ROS increase in the anticancer effect of TZD? In C6 glioma cells, CGZ, and with less efficiency RGZ and PGZ, induce superoxyde anion and $\mathrm{ONOO}^{-}$production, mitochondrial depolarization and decrease in mitochondrial $\mathrm{pH}$. This result is in 
Citation: Grillier-Vuissoz I, Mazerbourg S, Boisbrun M, Kuntz S, Chapleur Y, et al. (2012) PPARy-independent Activity of Thiazolidinediones: A Promising Mechanism of Action for New Anticancer Drugs? J Carcinogene Mutagene S8:002. doi:10.4172/2157-2518.S8-002

accordance with the higher cytotoxicity of CGZ. Addition of the antioxidants (N-acetyl-L-cysteine (NAC) and Ebselen) and the nitric oxide synthase (NOS) inhibitors (L-NAME or 1400W) both prevent CGZ-induced glioma $\mathrm{C6}$ cell death showing that both $\mathrm{O}_{2}^{-}$and $\mathrm{NO}$ derived reactive species are the mediator of the PPAR-independent cell death $[53,54]$. In glioma cells A172, the antiproliferative effect of CGZ is also reduced in the presence of the antioxidant NAC [56]. The implication of ROS in the PPAR $\gamma$-independent activation of mitogenactivated protein kinase (MAPK) pathways by TZD has been described in several cell lines (Table 1) and will be mentioned in the next part.

\section{MAPK Activation}

The activation of MAPK, especially ERK1/2, is often associated with proliferation for instance in response to growth factors like EGF that is a target for some anticancer agents. The rapid activation of MAPK by PPAR agonists was first described with PPAR a agonists: these compounds induce the phosphorylation of ERK1/2 which contributes to the expression of immediate-early genes [57]. Since then, numerous studies have been performed in a large diversity of cell lines to determine if MAPKs were also activated following exposure to TZD. The PPAR $\gamma$-independence was not clearly demonstrated in all cases but it was often suggested since MAPK activation occurs rapidly and transiently after exposure to the compounds, that is surprising due to their anticancer action.

\section{ERK1/2 signaling pathway}

ERK1/2 phosphorylation transiently increases following TGZ treatment, peaking at 30 minutes and decreasing thereafter, in several human colorectal cancer cell lines (HCT15 and HT29 exposed to $20 \mu \mathrm{M}$; HCT116 exposed to $5 \mu \mathrm{M})$ [58,59]. In rat astrocytes and in preadipocytes, CGZ $(20 \mu \mathrm{M})$ induces a rapid activation of ERK1/2 that is detected after 15 minutes and sustained for 4 hours whereas the more potent PPAR $\gamma$ agonist RGZ (used at $20 \mu \mathrm{M}$ ) has no effect, suggesting a PPAR $\gamma$-independent mechanism [60]. The phosphorylation of ERK1/2 is also observed in mouse myoblast cells C2C12 exposed for 10-30 minutes to CGZ $(30 \mu \mathrm{M})$ and this event still occurs in the presence of the PPAR $\gamma$ antagonist BADGE [52]. In rat liver epithelial cells GN4, CGZ $(50 \mu \mathrm{M})$ induces a transient stimulation of ERK1/2 that reaches a peak at 10 minutes and declines to basal levels over 45 minutes whereas TGZ is inefficient [43]. In GN4 cells exposed for 10 minutes to the PPAR $\gamma$-inactive TZD $\Delta 2$-CGZ $(50 \mu \mathrm{M})$, ERK1/2 phosphorylation is also detected $[43,45]$. In human glioma cells A172, CGZ $(20 \mu \mathrm{M})$ induces a transient activation of ERK1/2 observed between 30 minutes and 3 hours [56]. In this study, although the PPAR $\gamma$ antagonist GW9662 was used in several experiments, the PPAR $\gamma$-independence of ERK1/2 activation was not tested. In the breast cancer cell line MCF-7, TGZ induces the activation of ERK1/2 with different kinetics according to studies: i) observed at 1 hour, peaking at 2 hours and decreasing to basal levels by 6 hours when used at $40 \mu \mathrm{M}$ [61], ii) after only 4 minutes of treatment and still detected after 18 hours when used at $25 \mu \mathrm{M}$ [38], iii) detected a soon as 5 minutes, increasing up to 45 minutes and decreasing up to 75 minutes when used at $25 \mu \mathrm{M}$ as observed with CGZ $(25 \mu \mathrm{M})$ [47]. In our study, ERK1/2 phosphorylation is clearly PPAR $\gamma$ independent since this event still occurs in the presence of the PPAR $\gamma$ inactive compound $\triangle 2$-TGZ but it is detected later, faintly at 15 minutes with an increase up to 75 minutes [47]. In contrast, exposure of MCF-7 cells to RGZ $(25 \mu \mathrm{M})$ does not trigger ERK1/2 activation [47]. In normal human urothelial cells (NHU), CGZ, TGZ and RGZ
$(10 \mu \mathrm{M})$ induce ERK1/2 activation with different kinetics: it peaks after 5 minutes following TGZ exposure and after 2-4 hours following CGZ or RGZ exposure [46].

From these different studies, it is clear that ERK1/2 is activated rapidly and transiently in various cell types after exposure to various TZD and that this occurs in a PAR $\gamma$-independent manner (Table 1). It is to notice that late activation of ERK1/2 following TZD treatment has also been described. For instance, TZD18, a dual PPAR $\alpha / \gamma$ agonist that inhibits breast cancer cell proliferation in a PPAR $\gamma$-independent manner, induces ERK1/2 phosphorylation at 1 hour and a peak at 8

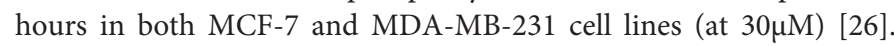
Nevertheless, the authors did not study early time points. In MCF7 breast cancer cells as well as in LNCaP prostate cancer cells, the PPAR $\gamma$-inactive TZD STG28 and OSU-CG12 (10-20 $\mu \mathrm{M})$ also induce an increase in ERK1/2 phosphorylation but this was studied 12 to 48 hours after treatment [31,62]. Regarding RGZ, although reported as inefficient in ERK1/2 activation in numerous studies, it is reported to induce this event when used at $10 \mu \mathrm{M}$ in human colon adenocarcinoma cells HT-29 where it peaks at 5-10 minutes [49]. The phosphorylation of ERK1/2 has also been observed 24 hours after exposure of lung

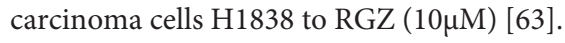

Data about the initiation of the ERK1/2 cascade are limited. The transactivation of the Epidermal Growth Factor Receptor (EGFR) leading to MEK1/2 phosphorylation is a proposed mechanism. This has been studied in detail in rat liver epithelial cells GN4. In these cells, CGZ $(50 \mu \mathrm{M})$ induces a rapid (5-10min) phosphorylation of EGFR on tyrosine residues and the pre-treatment with either PD153035 or ZD1839, two inhibitors of EGFR kinase activity, inhibits this CGZinduced modification of EGFR [64]. The transactivation of EGFR leads to Ras and MEK activation and ERK1/2 phosphorylation as suggested by the inhibitory effects of the dominant negative form RasN17 and the MEK inhibitor U0126 [64]. EGFR transactivation is downstream of the non-receptor tyrosine kinase Src since it is blocked by the Src inhibitor PP2. Moreover, following treatment with CGZ, EGFR is phosphorylated at $\mathrm{Tyr}^{845}$ that is a site for Src which is itself activated as shown by its phosphorylation at $\mathrm{Tyr}^{416}$ and its dephosphorylation on $\operatorname{Tyr}^{527}[43,65]$. The CGZ-induced activation of the EGFR/MEK/ERK1/2 cascade could involve reactive oxygen species (ROS) since NAC prevents its activation. EGFR and ERK1/2 phosphorylations are also observed in response to $\triangle 2$-CGZ $(50 \mu \mathrm{M})$, demonstrating the PPAR $\gamma$ independent nature of this pathway $[43,45]$. In contrast, TGZ and $\Delta 2$-TGZ $(50 \mu \mathrm{M})$ which do not induce ERK1/2 activation in GN4 cells also do not induce EGFR transactivation in these cells. Nevertheless, at $50 \mu \mathrm{M}$, both TGZ and $\Delta 2$-TGZ induce the phosphorylation of Src on $\mathrm{Tyr}^{416}$ [43]. In GN4 cells, the fact that only CGZ induces a capacitive $\mathrm{Ca}^{2+}$ entry could explain the differential effect of CGZ and TGZ on EGFR transactivation [43].

The events leading to the activation of the MAPK pathway in response to TZD have also been studied in other cell types. For instance, ROS are also upstream of the cascade leading to ERK1/2 activation in astrocytes and preadipocytes exposed to CGZ [60]. The activation of ERK1/2 following treatment of mouse myoblasts with CGZ requires Raf- 1 and MEK as well as ROS [52]. Raf- 1 and MEK are also upstream of ERK1/2 in colorectal cancer cells exposed to TGZ [58]. In the breast cancer cell line MCF-7, EGFR transactivation followed by MEK1/2 and ERK1/2 phosphorylation has also been described after TGZ 
Citation: Grillier-Vuissoz I, Mazerbourg S, Boisbrun M, Kuntz S, Chapleur Y, et al. (2012) PPARy-independent Activity of Thiazolidinediones: A Promising Mechanism of Action for New Anticancer Drugs? J Carcinogene Mutagene S8:002. doi:10.4172/2157-2518.S8-002

treatment [38]. However, in similar conditions, we could not confirm the involvement of EGFR in ERK1/2 activation [47]. Indeed, EGFR inhibitors (AG1478 and PD153035) and EGFR-targeted RNAi do not prevent the phosphorylation of ERK1/2 usually observed after $\Delta 2$-TGZ exposure. In our study, $\mathrm{Ca}^{2+}$ chelation by BAPTA inhibited TGZ- or CGZ-induced ERK1/2 activation [47]. This is very different from the situation of GN4 cells in which $\mathrm{Ca}^{2+}$ chelation by BAPTA does not affect the EGFR cascade.

The involvement of EGFR transactivation upstream of the cascade leading to ERK1/2 activation is further reinforced by experiments performed in porcine aorta endothelial (PAE) cells [65]. In these cells that are deficient in endogenous EGFR, TGZ does not induce ERK1/2 activation. This event only occurs when PAE cells are stably expressing human EGFR (PAE-EGFR): in such cells, TGZ and CGZ $(25-50 \mu \mathrm{M})$, but not RGZ and PGZ (up to $50 \mu \mathrm{M}$ ), activate EGFR-Grb2-ERK1/2 signaling. ERK1/2 activation is PPAR-independent since neither the antagonist GW9662 nor the transfection with a PPAR $\gamma$ dominant negative mutant is able to block TGZ-induced ERK1/2 phosphorylation [65]. In the same study, the authors show that TGZ may bind directly to EGFR and induces its endosomal internalization in 15-20 minutes. Furthermore, TGZ also induces the degradation of endogenous EGFR in the lung epithelial carcinoma cells A549 and prostate epithelial carcinoma cells Du145 [65]. CGZ also inhibits slightly the binding of EGF on its receptor whereas RGZ and PGZ do not.

\section{p38 MAPK signaling pathway}

As shown in Table 1, various TZD are able to induce p38 MAPK phosphorylation that is associated with ERK1/2 activation in most cases.

In astrocytes and preadipocytes treated with CGZ $(20 \mu \mathrm{M})$, the activation is detected from 15 minutes and sustained for several hours [60]. A transient activation of p38 is also observed in response to TGZ in human hepatoma cells HepG2 $(50 \mu \mathrm{M})$ and in breast cancer cells MCF-7 $(40 \mu \mathrm{M})$ occurring at 30 minutes and 1 hour respectively and reaching a maximum at 4 hours in both cases $[61,66]$. In rat liver epithelial cells GN4, p38 activation is observed early and transiently, from 2 to 15 minutes of treatment with both CGZ and TGZ whereas only CGZ is a potent inducer of ERK1/2 activation [64]. This event is independent of PPAR $\gamma$ since the PPAR $\gamma$-inactive derivatives $\Delta 2$ TGZ and $\triangle 2$-CGZ are also p38 activators (although less effective than their parent compounds) and since the antagonist GW9662 does not affect p38 phosphorylation observed following exposure to CGZ, TGZ or even their $\Delta 2$ derivatives [45]. Exposure of glioma cells to CGZ is also followed by an early transient activation of p38 that is maximal at 30 minutes [56]. In normal human urothelial cells, CGZ and TGZ trigger p38 activation [46]. The dual PPAR $\alpha / \gamma$ agonist TZD18 that inhibit breast cancer cell proliferation in a PPAR-independent manner induces p38 phosphorylation that is observed at 1 hour and peaks at 8 hours in both MCF-7 and MDA-MB-231 cell lines [26]. In LNCaP prostate cancer cells, STG28 also induces an increase in p38 phosphorylation after 12 hours of treatment, but this was not studied at earlier time points [62].

RGZ (50 $\mu \mathrm{M})$ does not trigger p38 activation in GN4 cells [45]. In contrast, in the human non small cell lung cancer cell line H1838 whose proliferation is inhibited by RGZ, p38 phosphorylation is observed after a 2 hours treatment at $10 \mu \mathrm{M}$ [63]. RGZ $(10 \mu \mathrm{M})$ is also a weak inducer of p38 phosphorylation in NHU cells [46]. It is also reported as a data not shown that PGZ treatment does not induce p38 activation in GN4 cells [45].

Little is known concerning the p38 MAPK upstream signal. ROS production could participate in $\mathrm{p} 38$ activation following TZD treatment since NAC antagonizes this effect of CGZ in astrocytes [60]. This is consistent with the observation that ROS are produced following treatment of fibrosarcoma cells HT1080 and glioma cells A172 with CGZ [51,56]. Nevertheless, NAC does not antagonize p38 MAPK phosphorylation after exposure of rat liver epithelial cells GN4 to CGZ [45]. In these cells, $\mathrm{Ca}^{2+}$ could be involved in p38 activation. Indeed, the $\mathrm{Ca}^{2+}$ chelator BAPTA-AM inhibits the activation of $\mathrm{p} 38$ usually observed in response to either CGZ or TGZ [64]. Besides, pretreatment of GN4 cells with the CAMKII inhibitor KN-93 blocks p38 activation by CGZ and TGZ [45]. The link between $\mathrm{Ca}^{2+}$ and p38 activation is not clear in NHU cells since RGZ treatment stimulates p38 activation although it does not induce $\mathrm{Ca}^{2+}$ increase [46]

\section{JNK signaling pathway}

JNK (c-Jun $\mathrm{NH}_{2}$-terminal kinase) phosphorylation is observed concomitantly with the activation of ERK1/2 and p38 MAPK pathways with a profile of activation similar to p38 (Table 1). It has been described in response to CGZ $(20 \mu \mathrm{M})$ in astrocytes and preadipocytes and in response to TGZ $(40 \mu \mathrm{M})$ in breast cancer cells MCF-7 [60,61]. In hepatoma cells HepG2, TGZ $(50 \mu \mathrm{M})$ also triggers a transient activation of JNK (maximum at 4 hours) whereas RGZ at the same concentration does not [66].

The dual PPARa/ $\gamma$ agonist TZD18 $(30 \mu \mathrm{M})$ induces JNK phosphorylation that is observed at 1 hour and peaks at 8 hours in both MCF-7 and MDA-MB-231 cell lines [26].

Except in astrocytes where ROS are presented as the upstream signal after CGZ treatment, no data are available on the activator signal of the JNK signaling cascade [60].

What is the importance of these different MAPK pathways in the anticancer action of TZD? In glioma cells A172, neither PD98059 (inhibitor of MEK1/2), nor SB203580 (inhibitor of p38) or SP600125 (inhibitor of JNK) are able to affect CGZ-induced cell death [56]. However, the effect of CGZ is reduced in the presence of the antioxidant NAC. In normal human urothelial cells, the cell death induced by CGZ is not affected by the inhibition of p38 by SB203580 [46]. In PAEEGFR cells, the inhibition of MEK1/2 by PD 98059 does not modify the antiproliferative action of TGZ [65]. In breast cancer cells MCF-7, the inhibition of MEK1/2 or p38 (by PD98059 and SB203580 respectively) enhances the induction of apoptosis induced by TGZ whereas the inhibition of JNK by SP600125 reduces it [61]. These effects are in agreement with the induction of the DNA damage-inducible gene 45 (GADD45). In hepatoma cells HepG2, the inhibition of JNK either by SP600125 or by a dominant-negative form of the kinase decreases TGZ-induced apoptosis whereas inhibition of p38 has no effect [66] In lung cancer cells NCI-H23, differentiation and apoptosis induced by TGZ are ERK1/2-dependent [67]. In the breast cancer cells MCF7 and MDA-MB-231, ERK1/2, p38 and JNK are individually partially involved in the effect of the dual PPAR $\alpha / \gamma$ agonist TZD18 which inhibits the cell growth in a PPAR-independent manner [26]. In MCF-7 cells, we have shown that CGZ, TGZ and $\triangle 2$-TGZ stimulate the transient expression of Early Growth Response gene 1 (EGR1) 
Citation: Grillier-Vuissoz I, Mazerbourg S, Boisbrun M, Kuntz S, Chapleur Y, et al. (2012) PPARy-independent Activity of Thiazolidinediones: A Promising Mechanism of Action for New Anticancer Drugs? J Carcinogene Mutagene S8:002. doi:10.4172/2157-2518.S8-002

in an ERK1/2-dependent-manner and that the inhibition of EGR1 expression by siRNA decreases the antiproliferative effect of $\Delta 2$-TGZ [47]. In the same cell line, the EGFR antagonist AG1478 that inhibits TGZ-induced activation of ERK1/2 does not prevent TGZ-induced inhibition of DNA synthesis [38].

Taken together these data indicate that MAPK activation is often associated with TZD exposure but if this is a key element of the anticancer action of TZD is still an open question due to conflicting results.

\section{Endoplasmic Reticulum Stress}

The endoplasmic reticulum (ER) is the organelle responsible for protein synthesis, folding and trafficking and it is also an important site for calcium storage. Several changes like alteration of the N-glycosylation machinery or modification of the $\mathrm{Ca}^{2+}$ level can induce an ER stress that impairs ER function. This leads to misfolded or unfolded protein accumulation to which ER responds by an evolutionary conserved adaptative response known as the Unfolded Protein Response (UPR). Misfolded or unfolded proteins titrate the chaperone glucose-regulated protein 78 (GRP78) (also known as BiP) away from three proximal sensors of the UPR: i) the activated PKR-like ER kinase (PERK) which phosphorylates the eukaryotic initiation factor $2 \alpha($ IF $2 \alpha)$ on $\operatorname{Ser}^{51}$ to decrease protein translation, ii) the activated inositol-requiring enzyme $1 \alpha$ (IRE-1 $\alpha$ ) which gains endoribonuclease activity to cleave the Xboxbinding protein 1 (XBP-1) mRNA, resulting in the synthesis of a highly active transcription factor and iii) the activating transcription factor 6 (ATF6) which translocates to the golgi where it is cleaved and then translocates to the nucleus to bind ER stress response elements. These transcription factors allow the expression of genes encoding chaperones to increase the protein folding activity in the ER (for review see [68]). However, when ER function is too much impaired and cannot be rescued by the UPR, the organelle elicits an ER stress-mediated apoptosis. Thus, compounds leading to a severe and prolonged ER stress could be interesting to develop an anticancer therapy [69].

CGZ and TGZ $(25 \mu \mathrm{M})$ have been shown to induce eIF2 $\alpha$ phosphorylation in both PPAR $\gamma^{+/+}$and $\operatorname{PPAR} \gamma^{-/}$mouse embryonic stem (ES) cells, suggesting a PPAR $\gamma$-independent effect [40]. This is observed as early as 30 minutes after exposure to these TZD. In NIH3T3 cells, this event is mediated by PKR (protein kinase activated by dsRNA) since the expression of the dominant-negative form (PKR-K296) prevents the phosphorylation of the PKR target, eIF2 $\alpha$ on $\mathrm{Ser}^{51}$. Phosphorylation of eIF2 $\alpha$ was used together with $\mathrm{Ca}^{2+}$ depletion and lung cancer cell growth inhibition (A549 cells) in order to screen for TZD derivatives as anticancer agents $[41,42]$.

Treatment of rat liver epithelial cells GN4 with CGZ and TGZ $(50 \mu \mathrm{M})$ induces a time-dependent phosphorylation of PERK [45]. This occurs in 5-10 minutes following exposure to these TZD. However, $\triangle 2$-CGZ and $\Delta 2$-TGZ $(50 \mu \mathrm{M})$ are unable to activate PERK in these cells. Using a phospho-specific antibody that detects eIF2 $\alpha$ when phosphorylated at Ser ${ }^{51}$, these authors observe that both CGZ and TGZ $(50 \mu \mathrm{M})$ induce eIF $2 \alpha$ phosphorylation at this site as early as 15 minutes after treatment. $\Delta 2$ derivatives are less effective in eIF $2 \alpha$ activation than their parent compounds. TGZ induces a greater PKR activation than CGZ not only in GN4 cells but also in human lung carcinoma cells (A549) [45]. The CAMKII inhibitor KN-93 significantly inhibits PKR and eIF2 $\alpha$ phosphorylation in response to CGZ and TGZ but it is not able to prevent PERK activation.
ER stress activation has been studied more completely in breast cancer cells [26]. A microarray analysis of MCF-7 and MDA-MB-231 cells treated for 24 hours with $30 \mu \mathrm{M}$ TZD18 reveals that many genes involved in ER stress signaling are up-regulated. The activation of ER stress suggested by this analysis is confirmed by several observations: phosphorylation of PERK and eIF2 $\alpha$, up-regulation of the chaperone GRP78 and activation of ATF6. ATF6 is up-regulated and processed to a $50 \mathrm{KDa}$ short form as early as 4 hours post-treatment. IRE1a is activated as shown by the cleavage of XBP-1 mRNA, resulting in the synthesis of a highly active transcription factor. This event occurs as early as 4 hours after addition of TZD18 to MDA-MB-231 cells. However, this event does not appear in MCF-7 cells. Besides, TZD18 induces the expression of ER stress-related cell death regulators such as CHOP, DR5, GADD34, Bax and Bak. These events are observed between 8 and 24 hours after TZD 18 treatment. The authors indicate in this paper as data not shown that i) PGZ does not induce ER stress in these two cell lines and ii) TZD18 does not induce ER stress in normal MCF-10A cells. Although they demonstrate that growth inhibition and apoptosis are PPAR-independent events, they do not demonstrate that ER stress itself is triggered in a PPAR-independent manner.

Data about the PPAR $\gamma$-independent induction of ER stress by TZD were obtained mainly in prostate cancer cells LNCaP by the use of two PPAR $\gamma$-inactive TZD derivatives: STG28 (TGZ derivative) and OSU-CG12 (CGZ family) [31]. STG28 and OSU-CG12 display antiproliferative potencies towards $\mathrm{LNCaP}$ cells with $\mathrm{IC}_{50}$ values around 10 and $5 \mu \mathrm{M}$ respectively whereas they display poor toxicity towards nonmalignant prostate epithelial cells. After 48 hours of exposure to $5 \mu \mathrm{M}$ of OSU-CG12, LNCaP cells show an up-regulation of IRE- $1 \alpha$ and the chaperone GRP78. An up-regulation of CHOP is also observed at this time, but it seems to appear only in case of treatment with higher doses $(10-20 \mu \mathrm{M})$. The PPAR $\gamma$-inactive TGZ derivative, STG 28, induces the same changes in LNCaP cells when used at 10 $20 \mu \mathrm{M}$. The authors also describe the phosphorylation of eIF2 $\alpha$ at Ser ${ }^{51}$ which appears clearly after 6 hours of exposure to OSU-CG12 $(10 \mu \mathrm{M})$.

What is the importance of ER stress in the anticancer action of TZD? NIH3T3 cells stably transfected with a vector expressing either the non phosphorylatable and inactive form of eIF2 $\alpha$ (eIF2 $\alpha-51 \mathrm{~A}$ ) or a dominant-negative form of PKR (PKR-K296) are resistant to the DNA synthesis inhibitory effects of CGZ and TGZ [40]. The knockdown of CHOP by siRNA antagonizes TZD18-induced apoptosis of MCF-7 and MDA-MB-231 breast cancer cells, showing an important role of $\mathrm{CHOP}$ and ER stress in the apoptotic process triggered by TZD18 [26]. In contrast, a similar approach of silencing of $\mathrm{CHOP}$ in the prostate cancer cells $\mathrm{LNCaP}$ has no effect on the susceptibility to the antiproliferative action of OSU-CG12 and on the cleavage of PARP [31].

\section{Proteolytic Events}

The degradation of proteins by the proteasome is an important mechanism involved in the regulation of various cellular functions. One of the PPAR $\gamma$-independent mechanisms of action of TZD is to facilitate the proteasomal degradation of a series of proliferation and apoptosis regulatory proteins including $\mathrm{ER} \alpha, \mathrm{c}-\mathrm{Myc}$, cyclin $\mathrm{D} 1, \beta$-catenin, and Sp1. This is not performed by modifications of the activity of the proteasome but by modifications affecting target proteins and their regulators.

\section{ERa}

A powerful regulator of cell proliferation in hormone-dependent breast cancer cells is the Estrogen Receptor alpha (ERa). A western 
Citation: Grillier-Vuissoz I, Mazerbourg S, Boisbrun M, Kuntz S, Chapleur Y, et al. (2012) PPARy-independent Activity of Thiazolidinediones: A Promising Mechanism of Action for New Anticancer Drugs? J Carcinogene Mutagene S8:002. doi:10.4172/2157-2518.S8-002

blot study of MCF-7 breast cancer cells shows after 12 hours of incubation with $40-100 \mu \mathrm{M}$ CGZ a down-regulation of ERa that is complete at $80 \mu \mathrm{M}$ [70]. This effect does not occur in the presence of the proteasomal inhibitor MG132. The down-regulation of ERa following treatment with CGZ has been confirmed in another study [71]. The authors also observe it with TGZ and they indicate as data not shown that in contrast, RGZ and PGZ lacked appreciable effects at comparable concentration although they are more active in PPAR $\gamma$ activation, suggesting a PPAR $\gamma$-independent mechanism. This point was clearly demonstrated in our lab by the fact that TGZ-induced proteolysis of ERa still occurs in the presence of PPAR $\gamma$ antagonists (T0070907 and BADGE) and in cells transfected with siRNA directed against PPAR $\gamma$ [72]. Furthermore, ER $\alpha$ proteasomal degradation is also observed following treatment with various PPAR $\gamma$-inactive TZD derivatives including $\Delta 2$-CGZ, $\Delta 2$-TGZ, and OSU-CG12 [31,71-73]. The proteasomal degradation of ERa is not restricted to MCF-7 cells since it also occurs in the estrogen-dependent breast cancer cell line ZR75 [72]

\section{c-Myc}

The pro-oncogene c-Myc is a basic helix-loop-helix leucine zipper transcription factor commonly dysregulated in cancer, resulting in pleiotropic effects on cell proliferation, cell survival, angiogenesis, and metastasis [74]. In prostate cancer cells, TGZ induces a decrease of c-Myc at both the mRNA and protein levels. A 48 hours treatment by the proteasome inhibitor MG132 reverses the effect of TGZ, indicating a proteasomal degradation of the protein. Indeed TGZ increases the phosphorylation of c-Myc protein at $\mathrm{Thr}^{58}$, a crucial site for $\mathrm{c}-\mathrm{Myc}$ ubiquitination and its further proteasomal degradation $[75,76]$. The PI3K/AKT pathway could mediate this effect since only the inhibition of the PI3K is effective to block c-Myc degradation induced by TGZ. JNK, ERK $1 / 2$ and GSK3 $\beta$ are likely not involved. Moreover, using the PPAR $\gamma$ antagonist GW9662 and siRNA directed against PPAR $\gamma$, these authors demonstrate the PPAR $\gamma$-independence of TGZ-induced c-Myc degradation.

\section{Cyclin D1}

Cyclin D1 is a major regulator of cell cycle progression and triggers a multitude of proliferative and transforming signaling pathways [77]. In MCF-7 breast cancer cells, after 15 hours of incubation with $80 \mu \mathrm{M}$ CGZ, there is a down-regulation of cyclin D1 [70]. This is the consequence of proteasomal degradation since this event does not appear when CGZ treatment is performed in the presence of the proteasome inhibitor MG132. This result is confirmed by Huang et al. [71] who also show cyclin D1 ubiquitination and demonstrate the PPAR $\gamma$-independence of this event [71]. First, they show the degradation of cyclin D1 following treatment with CGZ and TGZ, but not with RGZ and PGZ which are two more potent activators of PPAR $\gamma$. Second, the degradation of cyclin D1 triggered by TGZ still occurs in the presence of the PPAR $\gamma$ antagonist GW9669. Besides, various PPAR $\gamma$-inactive TZD ( $\Delta 2$-CGZ, $\Delta 2$-TGZ, $\Delta 2$ TG6, and STG28) also induce the degradation of cyclin D1 [71,78]. STG28 has a similar effect in LNCaP prostate cancer cells [62]. Other cyclins including A, B, D2, D3 and E, are not affected after 24 hours of TGZ or $\Delta 2$-TGZ treatment, indicating that the ablative effect is highly specific.

Biotinylated derivatives of the PPAR $\gamma$-inactive compound $\Delta 2$-TGZ ( $\mathrm{b} \Delta 2$-TGZ) have been designed in our team to increase the specificity of drug delivery to cancer cells which could express a high level of vitamin receptor [73]. In the breast cancer cell lines MCF-7 and MDA-
MB-231, b2-TGZ is more efficient than $\Delta 2-\mathrm{TGZ}$ to induce cyclin D1 proteasomal degradation. For instance, western blots analysis shows that cyclin D1 protein is degraded in MDA-MB-231 cells exposed for 24 hours to only $3 \mu \mathrm{M}$ of this compound whereas at this concentration, neither $\Delta 2$-TGZ nor TGZ are able to induce any modification of cyclin D1 level. In the same samples, cyclin B1 levels are not modified by any of these TZD confirming the specificity of the proteolysis. However, the reason for the higher antiproliferative potency of $\mathrm{b} \Delta 2$-TGZ is not the presence of biotin by itself since the potency does not change when free biotin is present in the culture medium and since other derivatives substituted at the same position on the phenolic group of the chromane moiety of $\Delta 2$-TGZ also display an increased activity [73].

\section{$\beta$-catenin}

$\beta$-catenin plays two important roles: at the plasma membrane, it regulates E-cadherin-mediated cell adhesion whereas in the cytosol and in the nucleus, it regulates through the Wnt signaling cascade, the transcription of target genes encoding key actors of cell proliferation and differentiation. It is well documented that $\beta$-catenin is tightly controlled by two ubiquitin-dependent proteasomal degradation pathways: adenomatous polyposis coli (APC)-axin/GSK3 $\beta / \beta \operatorname{TrCP}$ and APC/Siah1 $[79,80]$. Initial studies in differentiating preadipocytes indicated that TGZ induced the proteasomal degradation of $\beta$-catenin [81,82]. Similar results were obtained in hepatocytes and MCF-7 breast cancer cells but not in colon cancer cells HT29 and HCT116 [83]. The fact that TZD-induced $\beta$-catenin degradation is a PPAR $\gamma$ independent event was demonstrated later in prostate cancer cells [84]. First, these authors observe that, although LNCaP cells expressed lower levels of PPAR $\gamma$ relative to DU-145 and PC-3 cells, the three cell lines were equally susceptible to TGZ-mediated $\beta$-catenin downregulation. Second, they show that in PC3 cells, the presence of the PPAR $\gamma$ antagonist GW9662 does not inhibit this event. Third, siRNA knockdown of PPAR $\gamma$ in PC-3 cells has no effect on $\beta$-catenin downregulation. Fourth, they observe that $\beta$-catenin down-regulation also occurs following treatment of LNCaP cells with two PPAR $\gamma$-inactive TGZ derivatives ( $\triangle 2-\mathrm{TGZ}$ and STG28). These authors also studied in detail TZD-facilitated $\beta$-catenin down-regulation. The $\beta$-catenin mRNA level is not modified and the use of the proteasome inhibitor MG132 confirms that the down-regulation of $\beta$-catenin observed in LNCaP cells is the result of its proteasomal degradation. Furthermore, TGZ, $\Delta 2-$ TGZ and STG28 induce its ubiquitination [84].

\section{Sp1}

The transcription factor Sp1 also plays an important role in regulating key actors of cell proliferation, apoptosis and metastasis. Sp1 overexpression has been linked to poor prognosis in many human cancers, including prostate cancer where Sp1 controls androgen receptor (AR) expression [85]. In the prostate cancer cell line LNCaP, TGZ and $\Delta 2$-TGZ suppress AR expression with $\mathrm{IC}_{50}$ values of 40 and $30 \mu \mathrm{M}$ respectively [86]. STG28 is more potent than $\Delta 2$-TGZ and the parent compound TGZ to suppress AR expression in LNCaP cells [87]. This is associated with a decrease in AR mRNA level and an AR promoter-luciferase assay confirms that these agents are able to inhibit AR gene transcription in a dose-dependent manner. In fact, this modification of AR expression is the result of a decrease in Sp1 protein. On western blots, Sp1 detection decreases following treatment with TGZ, $\triangle 2-$ TGZ and STG28, an effect that does not occur in the presence of the proteasome inhibitors MG132 and epoxomycin [87]. In LNCaP cells, siRNA knockdown of $S p 1$ induces a decrease in AR mRNA after 24 hours and in AR protein after 48 hours. In cells transfected with a 
Citation: Grillier-Vuissoz I, Mazerbourg S, Boisbrun M, Kuntz S, Chapleur Y, et al. (2012) PPARy-independent Activity of Thiazolidinediones: A Promising Mechanism of Action for New Anticancer Drugs? J Carcinogene Mutagene S8:002. doi:10.4172/2157-2518.S8-002

pCMV-Sp1 vector, the overexpression of Sp1 protects the cells from the AR-ablative effect of STG28.

Using $\triangle 2$-CGZ to develop PPAR $\gamma$-independent AR-ablative agents, the authors obtained the compound 12 (named OSU-CG12 in later studies) which completely inhibits AR expression at low micromolar concentrations [88]. Like other PPAR $\gamma$-inactive TZD derivatives, OSU-CG12 triggers a down-regulation not only of Sp1 but also of cyclin $\mathrm{D} 1$ and $\beta$-catenin in both prostate (LNCaP) and breast (MCF-7) cancer cells, as described previously [31].

The proteasomal degradation of cyclin D1, $\beta$-catenin, and Sp1 seems to be the result of their ubiquitination by the Skp-Cullin-F box (SCF) E3 ubiquitin ligase $\beta$-TrCP. Indeed, western blot studies indicate that TGZ, $\Delta 2$-TGZ and STG28 induce an up-regulation of $\beta$-TrCP in LNCaP prostate cancer cells [84]. Besides, proteolytic events triggered by STG28 and/or OSU-CG12 are facilitated in cells overexpressing $\beta$-TrCP whereas they do not occur in cells transfected with siRNA targeting $\beta-\operatorname{TrCP}$ or expressing $\triangle \mathrm{F}-\beta-\operatorname{TrCP}$, which acts as a dominant negative because of the lack of the F-box motif $[31,84]$.

Regarding cyclin D1, immunoprecipitation studies indicate that $\beta-\operatorname{TrCP}$ associates with this cyclin following treatment with STG28. However, cyclin D1 is devoid of the consensus sequence DSGXnS $(\mathrm{X}=$ any $\mathrm{AA} ; \mathrm{n}=2-4)$ that is recognized by $\beta$-TrCP. Mutational and modeling analyses suggest that $\beta$-TrCP could target cyclin D1 through a nonconventional $\beta$-TrCP recognition site ${ }^{279} \mathrm{EEVDLACpT}^{286}$ in the prostate cancer cells LNCaP [62]. Moreover, following treatment of these cells with STG28, cyclin D1 proteolysis is preceded by its nuclear export and its phosphorylation on $\mathrm{Thr}^{186}$ [62]. The use of mutants reveals that $\mathrm{Thr}^{186}$ is required for both events. The IкB kinase $\alpha$ (IKKa) could phosphorylate cyclin D1 at this site following STG28 exposure since IKKa inhibitor (Bay11-7082), siRNA-mediated knockdown of IKKa as well as expression of a dominant negative IKKa mutant (IKK2M) protect LNCaP cells from STG28-triggered cyclin D1 proteolysis [62]. IKKa is phosphorylated on Ser ${ }^{180}$ following treatment of LNCaP cells with TGZ, CGZ and their PPAR $\gamma$-inactive derivatives STG28 and OSU-CG12 [31,62]. A similar response is observed in MCF-7 cells exposed to OSU-CG12 [31].

The recognition of $\beta$-catenin by $\beta$-TrCP seems to require the activity of the glycogen synthase kinase $3 \beta$ (GSK3 $\beta$ ). Indeed, in LNCaP cells, TGZ, $\Delta 2$-TGZ and STG28 induce a dose-dependent phosphorylation of GSK3 $\beta$ at Ser $^{9}$ as well as a dose-dependent increase in $\beta$-catenin phosphorylation at $\operatorname{Ser}^{33} / \mathrm{Ser}^{37} / \mathrm{Thr}^{41}$, a GSK3 $\beta$ phosphorylation site known to be recognized by $\beta$-TrCP [84]. Besides, GSK3 $\beta$ inhibitors ( $\mathrm{LiCl}$ and SB216763) protect LNCaP cells against STG28-facilitated $\beta$-catenin proteolysis.

Since exposure to STG28 does not affect $\beta$-TrCP mRNA level, this suggests that the increase in $\beta$-TrCP protein level is the result of its stabilisation. This is confirmed by an experiment using the protein synthesis inhibitor cycloheximide which allows to observe an increase in $\beta$-TrCP half-life following STG28 exposure. $\beta$-TrCP stabilisation is also described following treatment with the PPAR $\gamma$-inactive CGZ derivative OSU-CG12 not only in LNCaP prostate cancer cells but also in MCF-7 breast cancer cells [31]. The stabilisation of $\beta$-TrCP is a consequence of an early event: the transient up-regulation of Silent information regulator 1 (Sirt1) [31]. Indeed, RT-PCR and western blot analyses show that the mRNA and protein levels of this class III NAD ${ }^{+}$ dependent histone/protein deacetylase increase after 10 minutes of exposure of LNCaP cells to $10 \mu \mathrm{M}$ OSU-CG12. This increase is observed during 1 hour and is accompanied by changes in p53 acetylation levels. The inhibition of Sirtl deacetylase activity by nicotinamide or splitomicin, as well as the enforced expression of a dominant negative form of Sirt1 (H363YSirt1) inhibit the increase of $\beta$-TrCP usually observed in LNCaP cells exposed to OSU-CG12. Besides, ectopic expression of HA-tagged WT-Sirt1 mimics the effect of OSU-CG12 on increasing $\beta$-TrCP levels. Nevertheless, the increase in $\beta$-TrCP appears more than 10 hours after the increase in Sirt1. Furthermore, $\beta$-TrCP is not acetylated [31]. In contrast to these results obtained in prostate cancer cells, another study reports that TGZ $(25 \mu \mathrm{M})$ and high doses of CGZ $(100 \mu \mathrm{M})$ are able to inhibit histone deacetylase activity in breast cancer cells [89].

What is the importance of these proteolytic events in the anticancer action of TZD? The transfection of $\mathrm{LNCaP}$ cells with a vector expressing the dominant negative $\Delta \mathrm{F}-\beta$-TrCP (lacking the F-box motif) suppresses the sensitivity of these cells to the antiproliferative action of OSU-CG12 [31]. This experiment also shows an inhibition of PARP cleavage in comparison to control cells. Such an inhibition is also observed in cells expressing the dominant negative H363YSirt1. Interestingly, in contrast to LNCaP cells, exposure of normal prostate epithelial cells to STG28 does not induce $\beta$-TrCP accumulation that is consistent with the lack of $\beta$-catenin down-regulation [84]. Besides, in these cells, STG28 and OSU-CG12 do not cause a significant reduction of $\mathrm{Sp} 1$ or AR levels $[31,87]$. These data are correlated with the lower efficiency of STG28 and OSU-CG12 to inhibit cell proliferation in normal prostate epithelial cells compared to cancer cells.

\section{TZD as Energy Restriction Mimetic Agents}

Glucose deprivation induces $\beta$-TrCP-mediated proteolytic events in prostate (LNCaP) and breast (MCF-7) cancer cells $[31,62]$. This observation suggests that some PPAR $\gamma$-independent antitumor effects of TZD could be related to disruption of energy metabolism. This is in agreement with the fact that TGZ, CGZ, and the PPAR $\gamma$-inactive compounds STG28 and OSU-CG12 induce cellular responses similar to those of two energy restriction mimetic agents, 2-deoxyglucose (2-DG) and resveratrol [31]. This includes Sirt1 expression, ER stress and autophagy. In LNCaP cells, OSU-CG12 induces a dose- and time-dependent inhibition of the glycolytic rate which is paralleled by reductions in NADH and lactate formation. Besides, high levels of supplemental glucose protect LNCaP cells from OSU-CG12-induced cell death. In less than 20 minutes of OSU-CG12 exposure, there is a modest decrease in $\left[{ }^{3} \mathrm{H}\right] 2-\mathrm{DG}$ uptake. In RT-PCR analyses performed after 24 hours of treatment with OSU-CG12, there is a decrease in the mRNA levels of hexokinase 2 and phosphofructokinase-1, the first two enzymes of the glycolytic pathway. It might be interesting to determine if the energy restriction mimetic activity of TZD is also observed in other cell types and if other compounds of the $\Delta 2$ family also exert this activity. If energy restriction mimetic activity was a common mode of action of these compounds it could be interesting for cancer therapy due to the modified metabolism of cancer cells known as the Warburg's effect. This could explain the differential effects of these molecules between cancer cells and normal cells as illustrated in prostate with OSU-CG12 or STG28 [31].

\section{Towards Therapeutic Applications}

It is clear from the studies reported in this review that TZD exert PPAR $\gamma$-independent effects which are involved in the anticancer activity of these compounds. These effects have been observed in various cell types and then do not appear in a cell line specific manner. 


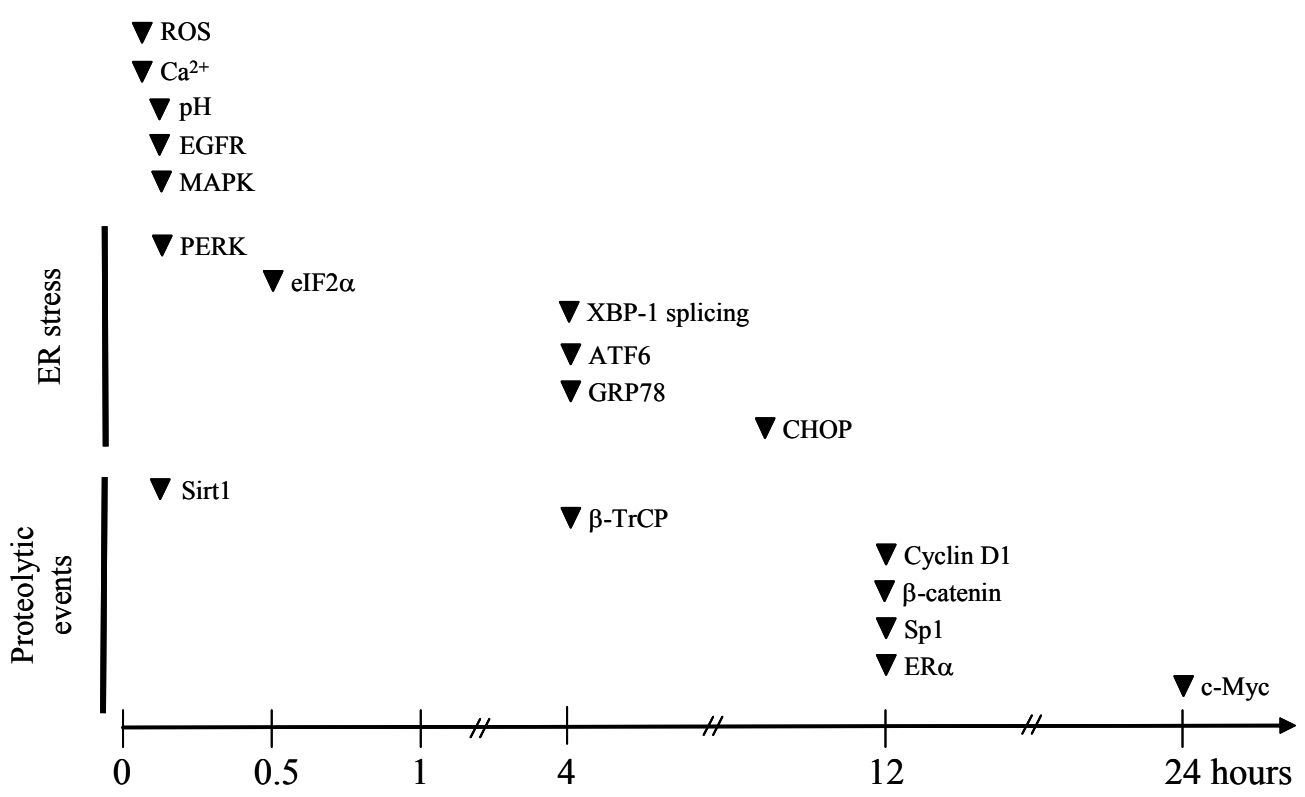

Figure 2: Chronology of the main events associated with the PPARY-independent activity of TZD.

Some of these effects like $\mathrm{pH}$ decrease, $\mathrm{Ca}^{2+}$ release from intracellular stores, ROS production and MAPK activation appear very early after exposure to TZD whereas some others like ER stress, and proteasomal degradations appear later (Figure 2). Nevertheless, it is still unclear if all these effects are interconnected. Indeed, they have never been studied in the same cell model. Besides, it has still to be determined if these events are the consequences of a common event occurring early in the cell following TZD exposure. An interesting perspective comes from the recent discovery that some TZD act as energy restriction mimetic agents and that energy restriction could initiate several PPAR $\gamma$-independent events including proteasomal degradations leading to apoptosis, ER stress and autophagy [31]. However, the potential relationships with earlier events like ionic changes have not been studied.

Among the original TZD that have been studied for their anticancer properties, it is also clear that although they belong to same family of molecules and bear the same 4'-hydroxy-5-benzilidene-thiazolidine2,4-dione residue (Figure 1), some of them behave very differently. This is especially true for RGZ and to a lesser extent for PGZ which in numerous studies are described as poorly efficient and sometimes inefficient not only in affecting cell viability but also in inducing the PPAR $\gamma$-independent events. Of course, it is interesting in order to highlight the PPAR $\gamma$-independent nature of the mechanisms, but one can ask for the reasons explaining such differences. For instance, in contrast to TGZ and CGZ, RGZ does not induce the release of intracellular $\mathrm{Ca}^{2+}$ nor inhibits the proliferation of the lung cancer cell line A549 [42]. The search for the minimum requirement for the substitution of the 4'-hydroxy group needed to maintain $\mathrm{Ca}^{2+}$ release revealed that the presence of a substitution on the 4'-hydroxyl group is essential and that there is a good correlation between lipophilicity and $\mathrm{Ca}^{2+}$ releasing activity [42]. In fact, in RGZ, an aminopyridine group is linked to the 4'-hydroxyl group, which rather confers some polarity to the molecule. PGZ bears a pyridine group at the same place, giving some polarity to the molecule too (Figure 1).
Since PPAR $\gamma$-independent events are involved in the anticancer effects of TGZ and CGZ, attention should be paid on their unsaturated derivatives ( $\triangle 2$ compounds) that are devoid of PPAR $\gamma$ agonist activity. Indeed, such compounds often appear more potent than the parent TZD at affecting cell viability. This might be explained by the fact that the PPAR $\gamma$-independent events triggered by $\Delta 2$ derivatives display some differences with those occurring in response to TGZ or CGZ. For instance, we observed in breast cancer cells that the kinetics of $\mathrm{Ca}^{2+}$ changes and MAPK activation were not exactly identical between $\Delta 2$ TGZ and TGZ [47]. However, it should be noticed that it is difficult to compare the efficiency of one compound used in two studies performed by different teams since the efficiency varies depending on the fetal calf serum (FCS) concentration in the culture medium (our unpublished observations) $[58,86]$. This could be explained either by an interaction between TZD and serum components or by a facilitated energy restriction mimetic action of TZD in low FCS containing medium.

It is possible to optimize the PPAR $\gamma$-independent activity of $\Delta 2$ TGZ and $\Delta 2$-CGZ. This is illustrated by several structure activity relationships studies performed using these molecules as scaffolds. In studies where cyclin D1 proteolysis is envisioned as a target, it is noticed that $\Delta 2$-TGZ is much more effective than TGZ in ablating cyclin D1 $[71,78]$. The introduction of an allyl moiety on the terminal hydroxyl function of the chromane core (resulting in $\Delta 2$-TG-6) increases dramatically the activity, since it induces a complete proteasomal degradation of the protein when used at $7.5 \mu \mathrm{M}$ for 24 hours (whereas $30 \mu \mathrm{M}$ of $\Delta 2$-TGZ is required). Adding in the same time a methoxy group on the central phenyl ring, yielding STG28, had a slight positive effect: $5 \mu \mathrm{M}$ is required for the same effect. This study also shows that the introduction of the polar succinic group in place of the allyl has a strong detrimental effect. Thus, this position should hold an apolar moiety. We have also reported the antiproliferative activity of new $\Delta 2$ TGZ derivatives bearing non polar moieties (or polar groups linked to the chromane ring with an apolar hydrocarbon chain) (Figure 3) at the same position and whose activity is in the micromolar range 


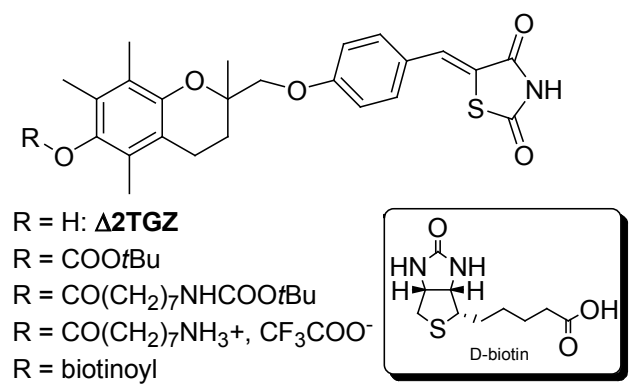<smiles>CC1(CN2C(=O)S/C(=C\c3ccc(NS(=O)(=O)c4ccc([N+](=O)[O-])c(C(F)(F)F)c4)cc3)C2=O)CCCCC1</smiles>

"Compound 53"

Figure 3: The various micromolar-active molecules prepared by Colin et al. [73] and the new AMPK-active compound 53 prepared by Guh et al. [90].

[73]. These $\Delta 2$-TGZ derivatives are also more potent inducers of ERa proteasomal degradation.

$\triangle 2$-CGZ was also used as a template to develop new molecules displaying an androgen receptor-ablative property [88]. The modification of the template which gives the best result consists in a permutational rearrangement of the terminal cyclohexyl moiety, yielding an inverted molecule where the TZD ring becomes central in the molecule, giving the so-called "compound 9" (Figure 1). Further functionalisation of the phenyl ring with a trifluoroacetate moiety gives the optimized compound OSU-CG12. Recently, the same team focused on adenosine monophosphate-activated protein kinase (AMPK) as a relevant target [90]. The introduction of an additive phenylsulfonamide on the latter template leads new compounds out of which the so-called "compound 53" gives the best results (Figure 3). With this knowledge in mind, efforts should now be concentrated on such $\Delta 2$-TGZ or $\Delta 2$ CGZ derivatives to get more active molecules.

A major concern in the development of a new compound lies in its toxicity. Regarding the TZD that were used as antidiabetic drugs, hepatic toxicity has only been reported for TGZ, leading to its withdrawal from the market in 2000 . Hence, one can hardly consider a class effect of TZD. The toxicity of TGZ has been studied in detail and the results were gathered by Yokoi in 2010 [11]. In brief, two parts of the molecule are considered for the observed toxicity. First, the TZD ring may react with numerous biomolecules including glutathione whose depletion could lead to cellular damages. But this could account for the toxicity of all the TZD derivatives. Second, biotransformation of the chromane heterocycle of TGZ could lead to reactive metabolites, especially quinone-type compounds among which some are highly toxic. Thus, it would be of high interest to study structure-toxicity relationships of the new TZD, at least towards human hepatocytes. For the molecules based on a $\triangle 2$-TGZ template, two questions are emerging: i) do the introduction of a double bond adjacent to the TZD ring (giving $\Delta 2$-TGZ from TGZ) decrease its affinity to biomolecules like glutathione? ii) do the various modifications of the chromane ring have an influence on reactive metabolites production? If one can prove that some of the new molecules show better properties than TGZ on these two points, these molecules could be considered for further development. Moreover, one can wonder if the presence of the TZD ring in a central position (as in OSU-CG12), instead of a lateral position, may also decrease its affinity to biomolecules, yielding less toxic compounds.

Finally, it should be kept in mind that another interesting therapeutic approach could be the use of $\triangle 2$-TZD derivatives at low doses in order to potentiate the anticancer activity of other compounds. Indeed, such an effect that is also PPAR $\gamma$-independent has been described for saturated TGZ and/or CGZ in various cell models in which they enhance TRAIL-induced apoptosis [58,91-94]. These effects are explained by several mechanisms including an increase of DR5 and a proteasomal degradation of c-FLIP and survivin. Interestingly, this effect is not observed in normal human mammary epithelial cells [91]. In glioma cell lines (MG-328, U-87MG and LN-18), TGZ can also act synergistically with chemotherapeutic agents like etoposide or taxol to induce apoptosis [92]. CGZ can also act synergistically with niflumic acid to induce apoptosis of lung cancer cells [95]. Similar potentiating effects have been described in the breast cancer cells MCF-7 exposed to a co-treatment with heregulin (HRG) and TGZ, which causes in a PPAR $\gamma$-independent manner apoptosis, necrosis and autophagy [96]. An increase in mitochondrial ROS could be involved since pretreatment with NAC reduces LC3-II expression, nuclear fragmentation (apoptosis) and DNA damage. Furthermore, catalase overexpression leads to the reduction of PARP cleavage [96]. In regard to facilitated cell death, RGZ has intriguing effects since despite this TZD displays no or poor activity when used alone, it can sensitize cells that are resistant to TRAIL: this is observed in the bladder cancer cell line T-24 and in human renal cancer cells $[27,50]$. Since pre-treatment with glutathione inhibits RGZ-induced DR5 up-regulation and TRAILinduced apoptosis, the production of ROS in response to RGZ could explain this particular effect. RGZ also potentiates breast cancer cells to TRAIL-induced apoptosis and this effect is confirmed in an in vivo xenograft model [91].

\section{Conclusion}

Numerous PPAR $\gamma$-independent effects of TZD have been described in the last decade. This contributed to the understanding of the anticancer effects of such compounds although some aspects have still to be elucidated. New derivatives devoid of PPAR $\gamma$ activity and displaying low toxicity could be developed in the next years. This would offer new perspectives for clinical studies and would be a very nice example of successful translational research.

\section{References}

1. Sohda T, Mizuno K, Imamiya E, Sugiyama Y, Fujita T, et al. (1982) Studies on antidiabetic agents. II. Synthesis of 5-[4-(1-methylcyclohexylmethoxy)-benzyl] thiazolidine-2,4-dione (ADD-3878) and its derivatives. Chem Pharm Bull (Tokyo) 30: 3580-3600.

2. Fujita T, Sugiyama Y, Taketomi S, Sohda T, Kawamatsu Y, et al. (1983) Reduction of insulin resistance in obese and/or diabetic animals by 5-[4-(1-methylcyclohexylmethoxy)benzyl]-thiazolidine-2,4-dione (ADD-3878, U-63,287, ciglitazone), a new antidiabetic agent. Diabetes 32: 804-810. 
Citation: Grillier-Vuissoz I, Mazerbourg S, Boisbrun M, Kuntz S, Chapleur Y, et al. (2012) PPARy-independent Activity of Thiazolidinediones: A Promising Mechanism of Action for New Anticancer Drugs? J Carcinogene Mutagene S8:002. doi:10.4172/2157-2518.S8-002

3. Fujiwara T, Yoshioka S, Yoshioka T, Ushiyama I, Horikoshi H (1988) Characterization of new oral antidiabetic agent CS-045. Studies in KK and ob/ ob mice and Zucker fatty rats. Diabetes 37: 1549-1558.

4. Forman BM, Tontonoz P, Chen J, Brun RP, Spiegelman BM, et al. (1995) 15-Deoxy-delta 12, 14-prostaglandin $\mathrm{J} 2$ is a ligand for the adipocyte determination factor PPAR gamma. Cell 83: 803-812.

5. Ibrahimi A, Teboul L, Gaillard D, Amri EZ, Ailhaud G, et al. (1994) Evidence for a common mechanism of action for fatty acids and thiazolidinedione antidiabetic agents on gene expression in preadipose cells. Mol Pharmacol 46: 1070-1076.

6. Lehmann JM, Moore LB, Smith-Oliver TA, Wilkison WO, Willson TM, et al. (1995) An antidiabetic thiazolidinedione is a high affinity ligand for peroxisome proliferator-activated receptor gamma (PPAR gamma). J Biol Chem 270: 12953-12956.

7. Feige JN, Gelman L, Michalik L, Desvergne B, Wahli W (2006) From molecular action to physiological outputs: peroxisome proliferator-activated receptors are nuclear receptors at the crossroads of key cellular functions. Prog Lipid Res 45: $120-159$

8. Chojkier M (2005) Troglitazone and liver injury: in search of answers. Hepatology 41: 237-246.

9. Gale EA (2006) Troglitazone: the lesson that nobody learned? Diabetologia 49: 1-6.

10. Alvarez-Sanchez R, Montavon F, Hartung T, PÃahler A (2006) Thiazolidinedione bioactivation: a comparison of the bioactivation potentials of troglitazone rosiglitazone, and pioglitazone using stable isotope-labeled analogues and liquid chromatography tandem mass spectrometry. Chem Res Toxicol 19: 1106-1116.

11. Yokoi T (2010) Troglitazone. Handb Exp Pharmacol : 419-435.

12. European-Medicines-Agency (2010) European medicines agency recommends suspension of avandia, avandamet and avaglim. Press release 09/23/2010.

13. Afssaps (2011) Use of Medications Containing Pioglitazone (Actos $®$, Competact $($ ) Suspended. Press release 06/09/2011

14. Lewis JD, Ferrara A, Peng T, Hedderson M, Bilker WB, et al. (2011) Risk of bladder cancer among diabetic patients treated with pioglitazone: interim report of a longitudinal cohort study. Diabetes Care 34: 916-922.

15. Burstein HJ, Demetri GD, Mueller E, Sarraf P, Spiegelman BM, et al. (2003) Use of the peroxisome proliferator-activated receptor (PPAR) gamma ligand troglitazone as treatment for refractory breast cancer: a phase II study. Breast Cancer Res Treat 79: 391-397.

16. Debrock G, Vanhentenrijk V, Sciot R, Debiec-Rychter M, Oyen R, et al. (2003) A phase II trial with rosiglitazone in liposarcoma patients. Br J Cancer 89: 14091412.

17. Kulke MH, Demetri GD, Sharpless NE, Ryan DP, Shivdasani R, et al. (2002) A phase II study of troglitazone, an activator of the PPARgamma receptor, in patients with chemotherapy-resistant metastatic colorectal cancer. Cancer $J$ 8: 395-399.

18. Home PD, Pocock SJ, Beck-Nielsen H, Curtis PS, Gomis R, et al. (2009) Rosiglitazone evaluated for cardiovascular outcomes in oral agent combination therapy for type 2 diabetes (RECORD): a multicentre, randomised, open-label trial. Lancet 373: 2125-2135.

19. Monami M, Lamanna C, Marchionni N, Mannucci E (2008) Rosiglitazone and risk of cancer: a meta-analysis of randomized clinical trials. Diabetes Care 31 : $1455-1460$.

20. Mueller E, Smith M, Sarraf P, Kroll T, Aiyer A, et al. (2000) Effects of ligand activation of peroxisome proliferator-activated receptor gamma in human prostate cancer. Proc Natl Acad Sci U S A 97: 10990-10995.

21. Kebebew E, Peng M, Reiff E, Treseler P, Woeber KA, et al. (2006) A phase II trial of rosiglitazone in patients with thyroglobulin-positive and radioiodinenegative differentiated thyroid cancer. Surgery 140: 960-966.

22. Read WL, Baggstrom MQ, Fracasso PM, Govindan R (2008) A phase I study of bexarotene and rosiglitazone in patients with refractory cancers. Chemotherapy 54: $236-241$
23. Shiau CW, Yang CC, Kulp SK, Chen KF, Chen CS, et al. (2005) Thiazolidenediones mediate apoptosis in prostate cancer cells in part through inhibition of $\mathrm{Bcl}-\mathrm{xL} / \mathrm{Bcl}-2$ functions independently of PPARgamma. Cancer Res 65: 1561-1569.

24. Weng JR, Chen CY, Pinzone JJ, Ringel MD, Chen CS (2006) Beyond peroxisome proliferator-activated receptor gamma signaling: the multi-facets of the antitumor effect of thiazolidinediones. Endocr Relat Cancer 13: 401-413.

25. Wei S, Yang J, Lee SL, Kulp SK, Chen CS (2009) PPARgamma-independent antitumor effects of thiazolidinediones. Cancer Lett 276: 119-124.

26. Zang C, Liu H, Bertz J, Possinger K, Koeffler HP, et al. (2009) Induction of endoplasmic reticulum stress response by TZD18, a novel dual ligand for peroxisome proliferator-activated receptor alpha/gamma, in human breast cancer cells. Mol Cancer Ther 8: 2296-2307.

27. Plissonnier ML, Fauconnet S, Bittard H, Lascombe I (2010) Insights on distinct pathways of thiazolidinediones (PPARgamma ligand)-promoted apoptosis in TRAIL-sensitive or -resistant malignant urothelial cells. Int J Cancer 127: 17691784.

28. de Bruin EC, Medema JP (2008) Apoptosis and non-apoptotic deaths in cancer development and treatment response. Cancer Treat Rev 34: 737-749.

29. Eisenberg-Lerner A, Bialik S, Simon HU, Kimchi A (2009) Life and death partners: apoptosis, autophagy and the cross-talk between them. Cell Death Differ 16: 966-975

30. Yan J, Yang H, Wang G, Sun L, Zhou Y, et al. (2010) Autophagy augmented by troglitazone is independent of EGFR transactivation and correlated with AMPactivated protein kinase signaling. Autophagy 6: 67-73.

31. Wei S, Kulp SK, Chen CS (2010) Energy restriction as an antitumor target of thiazolidinediones. J Biol Chem 285: 9780-9791.

32. Zhou J, Zhang W, Liang B, Casimiro MC, Whitaker-Menezes D, et al. (2009) PPARgamma activation induces autophagy in breast cancer cells. Int $J$ Biochem Cell Biol 41: 2334-2342.

33. Vitale G, Zappavigna S, Marra M, Dicitore A, Meschini S, et al. (2011) The PPAR-gamma agonist troglitazone antagonizes survival pathways induced by STAT-3 in recombinant interferon-beta treated pancreatic cancer cells. Biotechnol Adv In press: August 2011

34. Cerquetti L, Sampaoli C, Amendola D, Bucci B, Masuelli L, et al. (2011) Rosiglitazone induces autophagy in $\mathrm{H} 295 \mathrm{R}$ and cell cycle deregulation in SW13 adrenocortical cancer cells. Exp Cell Res 317: 1397-1410.

35. Lee CH, Cragoe EJ Jr, Edwards AM (2003) Control of hepatocyte DNA synthesis by intracellular $\mathrm{pH}$ and its role in the action of tumor promoters. $\mathrm{J}$ Cell Physiol 195: 61-69.

36. de Dios ST, Hannan KM, Dilley RJ, Hill MA, Little PJ (2001) Troglitazone, but not rosiglitazone, inhibits $\mathrm{Na} / \mathrm{H}$ exchange activity and proliferation of macrovascular endothelial cells. J Diabetes Complications 15: 120-127.

37. Turturro F, Friday E, Fowler R, Surie D, Welbourne T (2004) Troglitazone acts on cellular $\mathrm{pH}$ and DNA synthesis through a peroxisome proliferator-activated receptor gamma-independent mechanism in breast cancer-derived cell lines. Clin Cancer Res 10: 7022-7030.

38. Friday E, Oliver R 3rd, Welbourne T, Turturro F (2007) Role of epidermal growth factor receptor (EGFR)-signaling versus cellular acidosis via $\mathrm{Na}+/ \mathrm{H}+$ exchanger1(NHE1)-inhibition in troglitazone-induced growth arrest of breast cancer-derived cells MCF-7. Cell Physiol Biochem 20: 751-762.

39. Pizzo P, Pozzan T (2007) Mitochondria-endoplasmic reticulum choreography: structure and signaling dynamics. Trends Cell Biol 17: 511-517.

40. Palakurthi SS, Aktas H, Grubissich LM, Mortensen RM, Halperin JA (2001) Anticancer effects of thiazolidinediones are independent of peroxisome proliferator-activated receptor gamma and mediated by inhibition of translation initiation. Cancer Res 61: 6213-6218.

41. Chen H, Fan YH, Natarajan A, Guo Y, lyasere J, et al. (2004) Synthesis and biological evaluation of thiazolidine-2,4-dione and 2,4-thione derivatives as inhibitors of translation initiation. Bioorg Med Chem Lett 14: 5401-5405. 
Citation: Grillier-Vuissoz I, Mazerbourg S, Boisbrun M, Kuntz S, Chapleur Y, et al. (2012) PPARy-independent Activity of Thiazolidinediones: A Promising Mechanism of Action for New Anticancer Drugs? J Carcinogene Mutagene S8:002. doi:10.4172/2157-2518.S8-002

42. Fan YH, Chen H, Natarajan A, Guo Y, Harbinski F, et al. (2004) Structureactivity requirements for the antiproliferative effect of troglitazone derivatives mediated by depletion of intracellular calcium. Bioorg Med Chem Lett 14: 2547 2550 .

43. Dewar BJ, Gardner OS, Chen CS, Earp HS, Samet JM, et al. (2007) Capacitative calcium entry contributes to the differential transactivation of the epidermal growth factor receptor in response to thiazolidinediones. Mol Pharmacol 72: 1146-1156.

44. Kawasaki J, Hirano K, Hirano M, Nishimura J, Fujishima M, et al. (1999) Troglitazone inhibits the capacitative $\mathrm{Ca} 2+$ entry in endothelial cells. Eur $\mathrm{J}$ Pharmacol 373: 111-120.

45. Gardner OS, Shiau CW, Chen CS, Graves LM (2005) Peroxisome proliferatoractivated receptor gamma-independent activation of p38 MAPK by thiazolidinediones involves calcium/calmodulin-dependent protein kinase II and protein kinase R: correlation with endoplasmic reticulum stress. J Biol Chem 280: 10109-10118.

46. Chopra B, Georgopoulos NT, Nicholl A, Hinley J, Oleksiewicz MB, et al. (2009) Structurally diverse peroxisome proliferator-activated receptor agonists induce apoptosis in human uro-epithelial cells by a receptor-independent mechanism involving store-operated calcium channels. Cell Prolif 42: 688-700.

47. Chbicheb S, Yao X, Rodeau JL, Salamone S, Boisbrun M, et al. (2011) EGR1 expression: a calcium and ERK1/2 mediated PPARY-independent event involved in the antiproliferative effect of 15-deoxy-1̂"12,14-prostaglandin $\mathrm{J} 2$ and thiazolidinediones in breast cancer cells. Biochem Pharmacol 81: 1087-1097.

48. Kim BY, Cho CH, Song DK, Mun KC, Suh SI, et al. (2005) Ciglitizone inhibits cell proliferation in human uterine leiomyoma via activation of store-operated Ca2+ channels. Am J Physiol Cell Physiol 288: C389-395.

49. Tencer L, Burgermeister E, Ebert MP, Liscovitch M (2008) Rosiglitazone induces caveolin-1 by PPARgamma-dependent and PPRE-independent mechanisms: the role of EGF receptor signaling and its effect on cancer cell drug resistance. Anticancer Res 28: 895-906.

50. Kim YH, Jung EM, Lee TJ, Kim SH, Choi YH, et al. (2008) Rosiglitazone promotes tumor necrosis factor-related apoptosis-inducing ligand-induced apoptosis by reactive oxygen species-mediated up-regulation of death receptor 5 and down-regulation of c-FLIP. Free Radic Biol Med 44: 1055-1068.

51. Kim KH, Cho YS, Park JM, Yoon SO, Kim KW, et al. (2007) Pro-MMP-2 activation by the PPARgamma agonist, ciglitazone, induces cell invasion through the generation of ROS and the activation of ERK. FEBS Lett 581: 3303-3310.

52. Huang WC, Chio CC, Chi KH, Wu HM, Lin WW (2002) Superoxide aniondependent Raf/MEK/ERK activation by peroxisome proliferator activated receptor gamma agonists 15-deoxy-delta(12,14)-prostaglandin $\mathrm{J}(2)$, ciglitazone, and GW1929. Exp Cell Res 277: 192-200.

53. Pérez-Ortiz JM-Ortiz JM, Tranque $P$, Vaquero CF, Domingo B, Molina F, et al. (2004) Glitazones differentially regulate primary astrocyte and glioma cell survival. Involvement of reactive oxygen species and peroxisome proliferatoractivated receptor-gamma. J Biol Chem 279: 8976-8985.

54. Pérez-Ortiz JM-Ortiz JM, Tranque P, Burgos M, Vaquero CF, Llopis J (2007) Glitazones induce astroglioma cell death by releasing reactive oxygen species from mitochondria: modulation of cytotoxicity by nitric oxide. Mol Pharmacol 72: $407-417$

55. Colca JR, McDonald WG, Waldon DJ, Leone JW, Lull JM, et al. (2004) Identification of a novel mitochondrial protein ("mitoNEET") cross-linked specifically by a thiazolidinedione photoprobe. Am J Physiol Endocrinol Metab 286: E252-E260.

56. Kang DW, Choi CH, Park JY, Kang SK, Kim YK (2008) Ciglitazone induces caspase-independent apoptosis through down-regulation of XIAP and survivin in human glioma cells. Neurochem Res 33: 551-561.

57. Rokos CL, Ledwith BJ (1997) Peroxisome proliferators activate extracellular signal-regulated kinases in immortalized mouse liver cells. J Biol Chem 272 : 13452-13457.

58. Kim JA, Park KS, Kim HI, Oh SY, Ahn Y, et al. (2002) Troglitazone activates
p21Cip/WAF1 through the ERK pathway in HCT15 human colorectal cancer cells. Cancer Lett 179: 185-195

59. Baek SJ, Wilson LC, Hsi LC, Eling TE (2003) Troglitazone, a peroxisome proliferator-activated receptor gamma (PPAR gamma) ligand, selectively induces the early growth response- 1 gene independently of PPAR gamma. A novel mechanism for its anti-tumorigenic activity. J Biol Chem 278: 5845-5853.

60. Lennon AM, RamaugÃ@ M, Dessouroux A, Pierre M (2002) MAP kinase cascades are activated in astrocytes and preadipocytes by 15-deoxyDelta(12-14)-prostaglandin $\mathrm{J}(2)$ and the thiazolidinedione ciglitazone through peroxisome proliferator activator receptor gamma-independent mechanisms involving reactive oxygenated species. J Biol Chem 277: 29681-29685.

61. Yin F, Bruemmer D, Blaschke F, Hsueh WA, Law RE, et al. (2004) Signaling pathways involved in induction of GADD45 gene expression and apoptosis by troglitazone in human MCF-7 breast carcinoma cells. Oncogene 23: 46144623.

62. Wei S, Yang HC, Chuang HC, Yang J, Kulp SK, et al. (2008) A novel mechanism by which thiazolidinediones facilitate the proteasomal degradation of cyclin D1 in cancer cells. J Biol Chem 283: 26759-26770.

63. Sun X, Ritzenthaler JD, Zheng Y, Roman J, Han S (2009) Rosiglitazone inhibits alpha4 nicotinic acetylcholine receptor expression in human lung carcinoma cells through peroxisome proliferator-activated receptor gamma-independent signals. Mol Cancer Ther 8: 110-118.

64. Gardner OS, Dewar BJ, Earp HS, Samet JM, Graves LM (2003) Dependence of peroxisome proliferator-activated receptor ligand-induced mitogen-activated protein kinase signaling on epidermal growth factor receptor transactivation. $J$ Biol Chem 278: 46261-46269.

65. Li X, Yang X, Xu Y, Jiang X, Li X, et al. (2009) Troglitazone inhibits cell proliferation by attenuation of epidermal growth factor receptor signaling independent of peroxisome proliferator-activated receptor gamma. Cell Res 19: $720-732$

66. Bae MA, Song BJ (2003) Critical role of c-Jun N-terminal protein kinase activation in troglitazone-induced apoptosis of human HepG2 hepatoma cells. Mol Pharmacol 63: 401-408.

67. Li M, Lee TW, Yim AP, Mok TS, Chen GG (2006) Apoptosis induced by troglitazone is both peroxisome proliferator-activated receptor-gamma- and ERK-dependent in human non-small lung cancer cells. J Cell Physiol 209: 428438.

68. Naidoo N (2009) ER and aging-Protein folding and the ER stress response. Ageing Res Rev 8: 150-159.

69. Healy SJ, Gorman AM, Mousavi-Shafaei P, Gupta S, Samali A (2009) Targeting the endoplasmic reticulum-stress response as an anticancer strategy. Eur J Pharmacol 625: 234-246.

70. Qin C, Burghardt R, Smith R, Wormke M, Stewart J, et al. (2003) Peroxisome proliferator-activated receptor gamma agonists induce proteasome-dependent degradation of cyclin D1 and estrogen receptor alpha in MCF-7 breast cancer cells. Cancer Res 63: 958-964.

71. Huang JW, Shiau CW, Yang YT, Kulp SK, Chen KF, et al. (2005) Peroxisome proliferator-activated receptor gamma-independent ablation of cyclin D1 by thiazolidinediones and their derivatives in breast cancer cells. Mol Pharmacol 67: 1342-1348.

72. Lecomte J, Flament S, Salamone S, Boisbrun M, Mazerbourg S, et al. (2008) Disruption of ERalpha signalling pathway by PPARgamma agonists: evidences of PPARgamma-independent events in two hormone-dependent breast cancer cell lines. Breast Cancer Res Treat 112: 437-451.

73. Colin C, Salamone S, Grillier-Vuissoz I, Boisbrun M, Kuntz S, et al. (2010) New troglitazone derivatives devoid of PPARy agonist activity display an increased antiproliferative effect in both hormone-dependent and hormone-independent breast cancer cell lines. Breast Cancer Res Treat 124: 101-110.

74. Eilers M, Eisenman RN (2008) Myc's broad reach. Genes Dev 22: 2755-2766

75. Akinyeke TO, Stewart LV (2011) Troglitazone suppresses c-Myc levels in human prostate cancer cells via a PPARy-independent mechanism. Cancer Biol Ther 11: 1046-1058. 
Citation: Grillier-Vuissoz I, Mazerbourg S, Boisbrun M, Kuntz S, Chapleur Y, et al. (2012) PPARy-independent Activity of Thiazolidinediones: A Promising Mechanism of Action for New Anticancer Drugs? J Carcinogene Mutagene S8:002. doi:10.4172/2157-2518.S8-002

Page 15 of 15

76. Sears RC (2004) The life cycle of C-myc: from synthesis to degradation. Cell Cycle 3: 1133-1137.

77. Musgrove EA, Caldon CE, Barraclough J, Stone A, Sutherland RL (2011) Cyclin D as a therapeutic target in cancer. Nat Rev Cancer 11: 558-572.

78. Huang JW, Shiau CW, Yang J, Wang DS, Chiu HC, et al. (2006) Development of small-molecule cyclin D1-ablative agents. J Med Chem 49: 4684-4689.

79. Fu Y, Zheng S, An N, Athanasopoulos T, Popplewell L, et al. (2011) $\beta$-catenin as a potential key target for tumor suppression. Int J Cancer 129: 1541-1551.

80. Liu C, Li Y, Semenov M, Han C, Baeg GH, et al. (2002) Control of beta-catenin phosphorylation/degradation by a dual-kinase mechanism. Cell 108: 837-847.

81. Moldes M, Zuo Y, Morrison RF, Silva D, Park BH, et al. (2003) Peroxisomeproliferator-activated receptor gamma suppresses Wnt/beta-catenin signalling during adipogenesis. Biochem J 376: 607-613.

82. Liu J, Farmer SR (2004) Regulating the balance between peroxisome proliferator-activated receptor gamma and beta-catenin signaling during adipogenesis. A glycogen synthase kinase 3beta phosphorylation-defective mutant of beta-catenin inhibits expression of a subset of adipogenic genes. $J$ Biol Chem 279: 45020-45027.

83. Sharma C, Pradeep A, Wong L, Rana A, Rana B (2004) Peroxisome proliferatoractivated receptor gamma activation can regulate beta-catenin levels via a proteasome-mediated and adenomatous polyposis coli-independent pathway. The Journal of Biological Chemistry 279: 35583-35594.

84. Wei S, Lin LF, Yang CC, Wang YC, Chang GD, et al. (2007) Thiazolidinediones modulate the expression of beta-catenin and other cell-cycle regulatory proteins by targeting the F-box proteins of Skp1-Cul1-F-box protein E3 ubiquitin ligase independently of peroxisome proliferator-activated receptor gamma. Mol Pharmacol 72: 725-733.

85. Sankpal UT, Goodison S, Abdelrahim M, Basha R (2011) Targeting Sp1 transcription factors in prostate cancer therapy. Med Chem 7: 518-525.

86. Yang CC, Ku CY, Wei S, Shiau CW, Chen CS, et al. (2006) Peroxisome proliferator-activated receptor gamma-independent repression of prostatespecific antigen expression by thiazolidinediones in prostate cancer cells. Mol Pharmacol 69: 1564-1570.

87. Yang CC, Wang YC, Wei S, Lin LF, Chen CS, et al. (2007) Peroxisome proliferator-activated receptor gamma-independent suppression of androgen receptor expression by troglitazone mechanism and pharmacologic exploitation. Cancer Res 67: 3229-3238.

88. Yang J, Wei S, Wang DS, Wang YC, Kulp SK, et al. (2008) Pharmacologica exploitation of the peroxisome proliferator-activated receptor gamma agonist ciglitazone to develop a novel class of androgen receptor-ablative agents. $J$ Med Chem 51: 2100-2107.

89. Davies GF, Ross AR, Arnason TG, Juurlink BH, Harkness TA (2010) Troglitazone inhibits histone deacetylase activity in breast cancer cells. Cancer Lett 288: 236-250.

90. Guh JH, Chang WL, Yang J, Lee SL, Wei S, et al. (2010) Development of nove adenosine monophosphate-activated protein kinase activators. J Med Chem 53: $2552-2561$

91. Lu M, Kwan T, Yu C, Chen F, Freedman B, et al. (2005) Peroxisome proliferatoractivated receptor gamma agonists promote TRAIL-induced apoptosis by reducing survivin levels via cyclin D3 repression and cell cycle arrest. J Bio Chem 280: 6742-6751.

92. Akasaki Y, Liu G, Matundan $\mathrm{HH}, \mathrm{Ng} \mathrm{H}$, Yuan X, et al. (2006) A peroxisome proliferator-activated receptor-gamma agonist, troglitazone, facilitates caspase- 8 and -9 activities by increasing the enzymatic activity of proteintyrosine phosphatase-1B on human glioma cells. J Biol Chem 281: 6165-6174.

93. Schultze K, Böck B, Eckert A, Oevermann L, Ramacher D, et al. (2006) Troglitazone sensitizes tumor cells to TRAIL-induced apoptosis via downregulation of FLIP and Survivin. Apoptosis 11: 1503-1512.

94. Zou W, Liu X, Yue P, Khuri FR, Sun SY (2007) PPARgamma ligands enhance TRAIL-induced apoptosis through DR5 upregulation and c-FLIP downregulation in human lung cancer cells. Cancer Biol Ther 6: 99-9106.

95. Kim BM, Maeng K, Lee KH, Hong SH (2011) Combined treatment with the Cox-2 inhibitor niflumic acid and PPARy ligand ciglitazone induces ER stress/ caspase-8-mediated apoptosis in human lung cancer cells. Cancer Lett 300 134-144.

96. Park BH, Lee SB, Stolz DB, Lee YJ, Lee BC (2011) Synergistic interactions between heregulin and peroxisome proliferator-activated receptor-gamma (PPARgamma) agonist in breast cancer cells. J Biol Chem 286: 20087-20099. 